\title{
Analisando e modificando o problema da separação de duas listas telefônicas com folhas intercaladas
}

\author{
Analyzing and modifying the problem of separating two interleaved phonebooks \\ Paulo Peixoto*1@, Rodolfo de Luna Oliveira ${ }^{2}$, José Alves Mendes Júnior ${ }^{1}$ \\ ${ }^{1}$ Núcleo de Formação Docente, Universidade Federal de Pernambuco, Caruaru, PE, Brasil \\ ${ }^{2}$ Instituto Federal de Alagoas, Santana do Ipanema, AL, Brasil
}

\begin{abstract}
Recebido em 18 de Junho de 2019. Revisado em 28 de Setembro de 2019. Aceito em 10 de Outubro de 2019
Neste artigo, analisamos em detalhes o problema da separação de duas listas telefônicas com folhas intercaladas, e propomos uma configuração alternativa que equivale à retirada das lombadas das listas. Mostramos - teórica e experimentalmente - que mesmo nessa configuração a separação das listas pode exigir forças elevadas.

Palavras-chave: listas telefônicas, atrito, modelagem.
\end{abstract}

In this paper, we analyze the problem of separating two interleaved phone books, and propose an alternative configuration that is equivalent to removing their spines. We show theoretically and experimentally that even in that configuration the separation of the phone books may require a lot of force.

Keywords: phone books, friction, modelling.

\section{Uma visão geral do problema}

Se você nasceu neste século ou na última década do século passado, muito provavelmente nunca manuseou uma lista telefônica impressa, mas já deve ter visto pela TV ou através da Internet uma impressionante demonstração do poder do atrito em que tenta-se separar, sem sucesso, duas listas com suas folhas intercaladas. Não há nada de especial no uso de listas telefônicas, a não ser por seu elevado número de folhas, que, como veremos, é o parâmetro mais importante nesse tipo de experimento. Listas telefônicas robustas chegam a ter 600 folhas, cada. Foi uma dessas listas, dividida ao meio (produzindo-se então dois volumes com 300 folhas, cada - que é ainda um número elevado) que a equipe do canal do YouTube Manual do Mundo usou em sua versão da experiência (publicada em 15 de janeiro de 2013) [1. Em outro vídeo (publicado 5 dias após), a equipe tentou separar as duas metades da lista com dois carros, mas o que conseguiram foi rasgar uma delas pela lombada [2]. Algo semelhante, porém em uma escala maior de força, já tinha sido exibido quatro anos antes: no dia 10 de setembro de 2008 foi ao ar pelo canal de televisão por assinatura Discovery Channel o episódio "Phone Book Friction" da série MythBusters (Caçadores de Mitos) [3]. (A parte inicial do episódio foi publicada no site YouTube pelo Discovery [4]). A equipe a princípio tentou separar duas listas telefônicas com 400 folhas, cada, com a ajuda de um número crescente de pessoas. Posteriormente, cada lista foi puxada por um carro, ainda sem êxito. Substituíram então os carros por dois tanques militares, que conseguiram enfim

*Endereço de correspondência: phrpeixoto@yahoo.com.br "separar" as listas pela aplicação de aproximadamente 3,6 toneladas-força em cada uma delas. No entanto, o mito da impossibilidade de separar as listas telefônicas não foi totalmente "caçado", porque as listas foram parcialmente rasgadas, e muitas folhas permaneceram não separadas. Isso não prova que é impossível separar duas listas telefônicas com suas folhas intercaladas; talvez o problema seja que, antes de atingir-se a força necessária para a separação, as listas rasguem. Voltaremos a essa discussão mais adiante.

Encontramos no YouTube outra realização dessa experiência [5], inicialmente com duas caminhonetes puxando as listas telefônicas - sem êxito. Substituindo as caminhonetes por dois potentes caminhões, o que a equipe conseguiu foi rasgar parcialmente as listas, pela aplicação de quase 2 toneladas-força. O vídeo foi publicado no dia 17 de dezembro de 2014. Meses antes, no dia 2 de maio de 2014, foi ao ar pelo canal de televisão France 5, na França, o episódio do programa (com proposta semelhante à do MythBusters - ou seja, realizar experiências para confirmar ou desmentir mitos populares) On n'est pas que des cobayes (Não Somos Só Cobaias) em que a equipe conseguiu erguer um carro de 600 quilogramas até 6 metros de altura - havendo entre o carro e o braço do guindaste duas listas telefônicas com folhas intercaladas. O mais interessante, naquela realização, não foi a intensidade da força suportada pelas listas (já vimos as listas enfrentarem desafios maiores), mas o fato de que a equipe do programa de TV propôs a um grupo de físicos o desafio de elucidar o enigma da suposta inseparabilidade das listas telefônicas. $\mathrm{O}$ resultado foi a publicação de um artigo por Alarcón e colaboradores, em janeiro de 2016, na conceituada revista científica Physical Review 
Letters [6]. Entre os autores, estão Christophe Poulard e Frédéric Restagno, que participaram do programa de TV.

Os artigos da revista Physical Review Letters não são organizados em seções, mas podemos identificar na publicação supracitada a seguinte estrutura: $\mathrm{O}$ texto começa com uma breve introdução, em que os autores apresentam o problema da separação de duas listas telefônicas com suas folhas intercaladas, e como ele foi abordado naquele trabalho, envolvendo medições sob condições controladas e o desenvolvimento de um modelo teórico que, segundo os autores, captura a física essencial necessária à elucidação do enigma. Ainda na parte introdutória do texto, são apresentados elementos da história da tribologia (definida em 1966 como "ciência e tecnologia de superfícies interagentes em movimento relativo e de assuntos e práticas relacionados" [7]), e em seguida é informado que as atividades nessa área têm alcançado micro e nanoescalas (envolvendo, por exemplo, nanotubos de carbono e folhas de grafeno - para os quais as leis clássicas do atrito, com as quais estamos tão familiarizados, não se aplicam). Os autores passam então à descrição do experimento, apresentando alguns resultados. Segue-se o desenvolvimento do modelo teórico, que ocupa apenas metade de uma página, mais uma página extra na forma de Material Suplementar. O artigo é concluído com comparações entre as previsões do modelo teórico e os resultados experimentais obtidos, e discussões pertinentes.

Ainda em janeiro de 2016, no dia 20, o trabalho publicado na Physical Review Letters foi divulgado em uma matéria do jornal português Público [8], de publicação diária e destinado à população em geral. Em uma parte do texto, a autora observa que o parâmetro de amplificação $\alpha$ - que constitui, segundo os autores do PRL 1$]$ o parâmetro adimensional central naquele estudo (veremos isso em detalhes na seção 2 - foi chamado, em postagem na revista de humor Improbable Research" ${ }^{2}$ de "número de Hércules", em referência ao herói da mitologia grega conhecido por sua força [11. Os autores do PRL passaram a adotar o termo, como vemos em um artigo de divulgação daquele trabalho publicado em junho de 2016 na revista Physics Today, escrito por parte da equip $\AA^{3}[13$. No mesmo mês, o autor do termo "número de Hércules" realizou outra postagem na revista Improbable Research, intitulada "The Hercules Number: How a Dimensionless Physical Parameter Got Its Name" [14] (talvez por não ter sido explicitamente citado, na publicação na Physics Today; eis suas primeiras palavras, na postagem: "I did

${ }^{1}$ Como costuma-se chamar um artigo publicado na revista Physical Review Letters.

${ }^{2}$ A revista Improbable Research divulga trabalhos de pesquisa "improváveis", "que fazem as pessoas rirem e depois pensarem" 9]. Trata-se de "pesquisa real, sobre tudo e qualquer coisa, de todos os lugares. Pesquisa que talvez seja boa ou ruim, importante ou trivial, valiosa ou inútil." A revista é mais conhecida pela criação e atribuição dos Prêmios IgNobel [10], que "se destinam a celebrar o inusitado, honrar os imaginativos - e estimular o interesse das pessoas por ciência, medicina e tecnologia." A expressão "IgNobel" é um trocadilho com "ignoble" ("ignóbil", em português), em associação a "Nobel".

${ }^{3}$ A revista Physics Today limita o número de autores por artigo a $3[12]$. not conceive or give birth to the Hercules Number. But I did name it. Here's the story.").

Mas, afinal, qual foi, em termos relativamente simples, a explicação dada no PRL para o problema da grande dificuldade de se separar duas listas telefônicas com folhas intercaladas? E em que consiste o número de Hércules?

Vamos por partes.

A Fig. 1ilustra duas listas telefônicas em repouso, com folhas intercaladas, cada uma delas sendo puxada com força de módulo $F$, com o uso de uma braçadeira. Na figura estão indicadas três regiões, para a lista da esquerda. A primeira é a região da braçadeira, que corresponde à parte das folhas envolvida pela braçadeira. Note que nessa região as folhas estão todas paralelas entre si, e à força $\mathbf{F}$. A terceira região é a região ou zona de contato, que é onde há contato entre as folhas das duas listas. A linha tracejada da esquerda indica até onde vão as folhas da lista da direita, e a linha tracejada da direita indica até onde vão as folhas da lista da esquerda. Uma dessas folhas está em destaque, na figura. Ao contrário do que sugerem essas linhas, esses limites não são perfeitamente planos, mas essa é uma das simplificações do modelo de Alarcón e colaboradores [6], que discutiremos na seção 2 A segunda região é a região ou zona intermediária. Nela, encontramos folhas da lista da esquerda, apenas, mas elas não estão envolvidas pela braçadeira (nem são paralelas entre si).

Pois bem, tentaremos fazer agora uma primeira tranposição didátice ${ }^{4}$ para a explicação dada no PRL para o problema da grande dificuldade de se separar duas listas telefônicas com folhas intercaladas.

Quando uma pequena força de módulo $F$ é aplicada em cada lista (veja a Fig. 1), elas não se movem, uma em relação à outra, devido ao atrito entre as folhas intercaladas, na zona de contato. Trata-se de atrito estático, e sabemos que, de acordo com as leis clássicas para o atrito, a força de atrito estático entre duas superfícies em contato possui um valor máximo, $f_{\mathrm{e}, \max }$, que depende do coeficiente de atrito estático $\mu_{\mathrm{e}}$ entre aquelas superfícies e do módulo $f_{\mathrm{n}}$ da força com que uma superfície

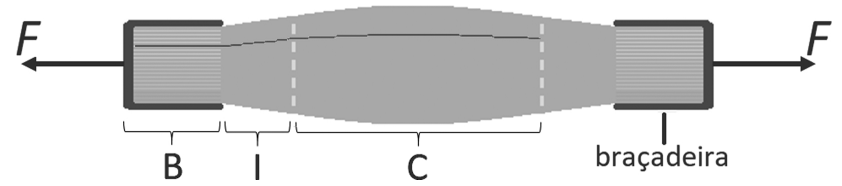

Figura 1: Ilustração de duas listas telefônicas em repouso, com folhas intercaladas, cada lista sendo puxada com força de módulo $F$. As regiões $\mathrm{B}, \mathrm{I}$ e $\mathrm{C}$ são, respectivamente, as regiões $d a \mathrm{Bra}$ çadeira, Intermediária e de Contato (para a lista da esquerda). Uma das folhas da lista da esquerda está em destaque.

\footnotetext{
${ }^{4}$ A teoria de transposição didática encontra no francês Yves Chevallard - inicialmente com a publicação de seu livro La Transposition Didactique, em 1985 - seu principal expoente. "Transposição didática" é um termo amplo, mas, no sentido que nos interessa aqui, fazer transposição didática significa adaptar conhecimento científico para que ele possa se transformar em conhecimento escolar (ou, ainda, em conhecimento universitário básico).
} 
é pressionada pela outra, perpendicularmente ao plano de contato: $f_{\mathrm{e}, \max }=\mu_{\mathrm{e}} f_{\mathrm{n}}$. Assim, poderíamos afirmar: aumentando continuamente o valor de $F$, em algum momento venceremos a força total de atrito estático entre as folhas na zona de contato, cujo módulo denotaremos por $F_{\mathrm{e}}$, já que ela possui um valor máximo, que denotaremos por $F_{\mathrm{e} \text {,max }}$. O problema é que esse valor máximo da força total de atrito estático também aumenta à medida que aumentamos o valor de $F$. Vamos explicar por quê.

Considere a lista telefônica da esquerda, na Fig.1, e sua folha em destaque. Tal folha, na região da braçadeira, é puxada para a esquerda com a mesma direção que a da força F. Contudo, devido ao desvio que a folha sofre quando passamos da região B para as regiões intermediária e de contato, ao ser puxada para a esquerda na região B ela é puxada para a esquerda e para baixo na região $\mathrm{I}{ }^{5}$ Assim, ao ser puxada para a esquerda com maior intensidade na região B, a folha é pressionada com maior intensidade contra a folha inferior (da outra lista) na região C. E isso, por sua vez, aumenta o valor máximo da força de atrito entre aquelas duas folhas. Isso se aplica às demais folhas da lista da esquerda (com exceção, talvez, da folha central - o que, de qualquer forma, tem efeito desprezível), exigindo, para a separação das listas, a aplicação de um maior valor de $F$ - que, por sua vez, torna a aumentar o valor máximo da força total de atrito estático, $F_{\mathrm{e}, \max }$.

Mas não devemos concluir, daí, que a força total de atrito estático entre as listas nunca seria superada. Tudo depende da forma como cresce seu valor máximo, $F_{\mathrm{e}, \max }$, quando aumentamos o módulo $F$ da força aplicada em cada braçadeira. As Figs.2a e 2p ilustram, qualitativamente, duas possibilidades. Em cada figura, a dependência de $F_{\text {e,max }}$ em relação a $F$ está indicada pela linha tracejada, enquanto a linha cheia indica a igualdade entre $F_{\mathrm{e}}$ e $F$ (significando que as listas estão em repouso, uma em relação à outra). No primeiro caso (Fig. 2a), a interseção entre as linhas cheia e tracejada indica o ponto onde o valor máximo da força total de atrito estático entre as listas é alcançado, correspondendo à situação de iminência de movimento. Qualquer aumento no valor $F$ da força aplicada, a partir daquele ponto, produz a

${ }^{5}$ Esta afirmativa merece uma análise detalhada, que faremos na seção 2 Por ora, apelaremos para a sua intuição física. separação das listas. No segundo caso (Fig.2p), tal interseção jamais ocorre, e em princípio as listas jamais são separadas. Mas, é claro, o valor de $F$ não poderia ser aumentado indefinidamente, porque em algum ponto as folhas de papel começariam a ser rasgadas. Aliás, mesmo na situação indicada na Fig. 2a as folhas de papel podem começar a rasgar antes do valor $F_{\text {e,max }}$ ser alcançado por $F$, se aquele valor é muito elevado. (A Fig. 2 c foi posta para comparação, e corresponde ao caso típico em que o valor de $F_{\text {e,max }}$ independe do valor de $F$.) Assim, se o valor máximo da força total de atrito estático entre as listas, $F_{\mathrm{e}, \max }$, pode ou não ser superado pela intensidade $F$ da força aplicada a cada lista depende da forma como aquele valor aumenta à medida que $F$ aumenta. Mas, repetimos: mesmo no primeiro caso, as folhas de papel podem começar a rasgar antes do valor $F_{\mathrm{e} \text {,max }}$ ser alcançado por $F$.

Como vimos, nas experiências relativas às referências 1 a 5 deste artigo as listas telefônicas ou não foram separadas ou foram rasgadas. Mas nos experimentos sob condições controladas realizados por Alarcón e colaboradores [6], as folhas foram separadas sem rasgo, e, portanto, a Fig. 2 a seria, dentre as apresentadas, a mais representativa da relação entre $F_{\mathrm{e} \text {,max }}$ e $F$. Não ter havido rasgo de folhas nos experimentos de Alarcón e colaboradores pode ter sido consequência, entre outros fatores, do número de folhas em cada grupo, que não excedeu o valor de 200 folhas. É que quanto maior o número de folhas em cada grupo, maior o valor de $F$ para o qual temos $F=F_{\text {e, max }}$ (veja a Fig. 2a), e denotaremos tal valor por $F_{\text {crítica }}{ }_{6}^{6} \mathrm{O}$ (rápido) aumento de $F_{\text {crítica }}$ com o aumento do número de folhas em cada grupo foi verificado experimentalmente por Alarcón e colaboradores, e é previsto por seu modelo teórico - que discutiremos em detalhes na seção 2 .

Recapitulando, a explicação dada no PRL por Alarcón e colaboradores para o problema da grande dificuldade de se separar duas listas telefônicas com folhas intercaladas foi, essencialmente, a seguinte:

quanto maior a intensidade $F$ da força aplicada a cada

${ }^{6}$ Exceto quando os autores trabalharam com um número pequeno de folhas em cada grupo, as forças necessárias à separação chegaram a quase 1000 newtons. O artigo de Alarcón e colaboradores sugere forças ainda maiores (veja a figura 2 daquele artigo), mas os dinamômetros usados pelos autores permitiram leituras de no máximo $1000 \mathrm{~N}$.

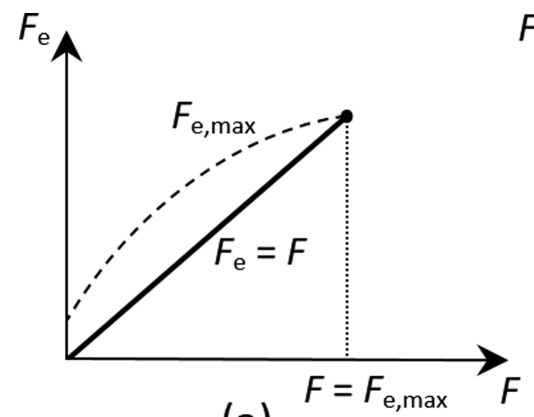

(a)

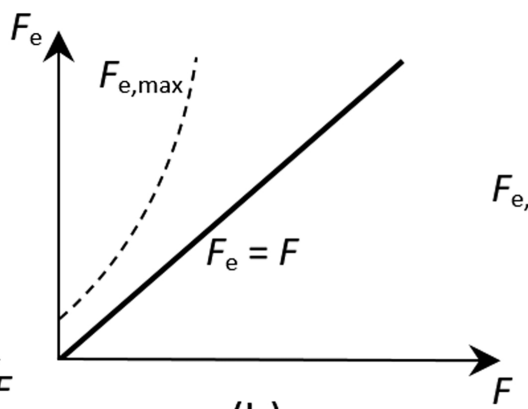

(b)

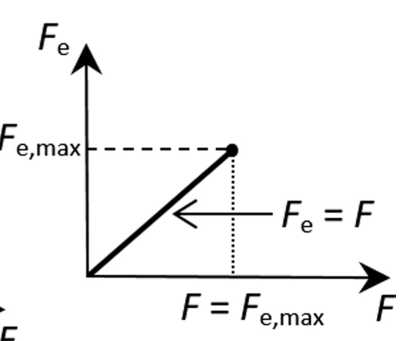

(c)

Figura 2: Força total de atrito estático entre as folhas na zona de contato, $F_{\mathrm{e}}$, em função da força $F$ aplicada em cada lista, considerando-se três formas de variação do valor máximo da força total de atrito estático, $F_{\mathrm{e}, \max }$, como função de $F$. 
lista (veja Fig.11), mais fortemente as folhas intercaladas são pressionadas umas contra as outras na zona de contato, e, consequentemente, maior o valor máximo da força total de atrito a ser vencida.

Esse efeito de amplificaçãd ${ }^{7}$ foi sugerido no episódio "Phone Book Friction" da série MythBusters [3] por um de seus apresentadores, quando disse:

I have a theory. I think there's more going on here than just friction of page on page. I think it has to do with the pages being stacked and the weight that they put on each other, as well as there may be some sort of a finger puzzle thing where the harder you pull the more it grabs.

(Eu tenho uma teoria. Eu acho que há mais acontecendo aqui do que apenas atrito de página sobre página. Eu acho que tem a ver com as páginas sendo empilhadas e o peso que elas colocam umas sobre as outras, assim como pode haver algum tipo de quebra-cabeça, onde quanto mais você puxa, mais se agarra.)

Infelizmente isso não foi citado pelos autores do PRL (que, contudo, citaram o referido episódio da série MythBusters (referência 2 daquele artigo)).

Quanto ao número de Hércules, ele é o parâmetro adimensional $\alpha=\mu_{\mathrm{c}} \epsilon N^{2} / 2 d$, em que $\mu_{\mathrm{c}}$ é o coeficiente de atrito cinético médid 8 entre as folhas de papel usadas no experimento, $\epsilon$ é a espessura de cada folha, $N$ é o número total de folhas em cada um dos dois grupos, e $d$ é um comprimento denominado no PRL "distância de separação da braçadeira à zona de contato" - que é a largura da zona intermediária (veja a Fig.1), medida paralelamente às forças de módulo $F$. O parâmetro $\alpha$ foi chamado no PRL de "parâmetro de amplificação" porque a principal equação daquele artigo prevê um rápido crescimento, quando o valor de $\alpha$ aumenta, para a força $F_{\text {crítica }}$ que põe as listas na iminência de movimento. Observe que, em particular, o valor de $\alpha$ cresce rapidamente

\footnotetext{
${ }^{7}$ Alarcón e colaboradores deram ao seu artigo 6] o seguinte título: "Self-Amplification of Solid Friction in Interleaved Assemblies". Mas preferimos a expressão "Amplification", no lugar de "SelfAmplification", porque visualizamos como agente amplificador do valor máximo da força total de atrito a força de intensidade $F$ aplicada a cada grupo de folhas (veja Figs.1 e 2 a), e não o próprio atrito.

${ }^{8}$ Os autores do PRL trabalharam em seu modelo com um coeficiente de atrito cinético, em vez de estático, em parte porque em seu experimento as folhas intercaladas foram movidas, umas em relação às outras; ou seja, as "listas" foram sempre separadas. Contudo, o movimento das folhas não foi contínuo: sua resposta à tração foi do tipo "stick-slip" ("gruda-escorrega" ou "cola-desliza") um fenômeno observado para muitos materiais [15] [16], incluindo papel 17]. Assim, os autores poderiam ter trabalhado com um valor intermediário entre o coeficiente de atrito cinético e o coeficiente de atrito estático para as folhas de papel usadas, já que no modelo foi considerado um movimento contínuo das folhas, em vez de um stick-slip. Mas, segundo os autores do PRL, a diferença entre os valores desses coeficientes pode ser desconsiderada no estudo realizado. E a ideia de se tomar um valor médio para o coeficiente de atrito cinético vem do fato experimental de que tal coeficiente é maior para pequenos valores de força normal (pequenas cargas) 6], podendo até ser superior a 1 para cargas muito reduzidas, devido a forças de adesão 18 .
}

com o aumento do número $N$ de folhas em cada lista. O modelo de Alarcón e colaboradores, portanto, prevê quantitativamente que com o aumento do número de folhas em cada lista a separação das listas vai se tornando rapidamente uma tarefa extremamente difícil.

Na próxima seção, descreveremos em detalhes o modelo de Alarcón e colaboradores. Fizemos um esforço para apresentar tal modelo de forma acessível a estudantes de graduação em física, engenharia ou área afim, que tenham cursado ao menos um semestre de mecânica newtoniana (a nível do Halliday [19], por exemplo) e um semestre de cálculo diferencial e integral.

Forneceremos agora mais algumas informações, para que possamos apresentar adequadamente as demais seções deste artigo - que não se limita à discussão do trabalho de Alarcón e colaboradores e à análise de eventos que o precederam.

Logo no início de seu artigo $\sqrt[6]{6}$, Alarcón e colaboradores afirmam (embora não haja nenhuma referência) que a explicação simples frequentemente dada para a enorme dificuldade de se separar duas listas telefônicas com suas folhas intercaladas é que a gravidade proporciona a força normal que gera o atrito tangencial entre as folhas. Daí afirmam que tal hipótese é facilmente provada incorreta, por não haver diferença discernível quando o experimento é realizado na direção vertical e na direção horizontal. Realizam então seu experimento sempre na direção vertical - ou seja, com as forças de módulo $F$ indicadas na Fig. 11na direção vertical. Mas o efeito da gravidade pode ser analisado realizando-se o experimento com as folhas em outra configuração, na qual não ocorre o fenômeno de amplificação do atrito: aquela indicada na Fig. 3 a. Observe na figura que cada braçadeira foi substituída por uma peça que não pressiona as folhas umas contra as outras. Trata-se de uma peça rígida, e as folhas são puxadas horizontalmente através de um conjunto de 10 pinos que as atravessam em furos previamente realizados (como em uma encadernação com espiral). Está indicada na figura a região $(\mathrm{C})$ onde há o contato entre as folhas dos dois grupos. Note que há um prolongamento da base da peça rígida da direita, para que as folhas se mantenham na direção horizontal. Sobre aquela base repousa a primeira folha do grupo de folhas à direita, e sobre esta repousa a primeira folha do grupo de folhas à esquerda, e assim as folhas dos dois grupos vão sendo intercaladas, mas com a última folha pertencendo ao grupo da direita, de modo que se há $N$ folhas no grupo da esquerda, há $N+1$ folhas no grupo da direita. Isto significa que cada folha do grupo da esquerda tem acima e abaixo dela uma folha do grupo da direita.

Na seção 4 descreveremos nossa realização do experimento correspondente à Fig. 3 a, e discutiremos os resultados obtidos. Você verá que, mesmo sem o efeito de amplificação do atrito, a separação dos dois grupos de folhas pode ser uma tarefa bastante difícil. E isso pode ser facilmente previsto teoricamente, de modo que optamos por apresentar essa previsão teórica antes da apresentação da realização experimental: na seção 3 deste artigo. O desenvolvimento é bastante simples, acessível a alunos do ensino médio. Faremos comparações com os resultados 


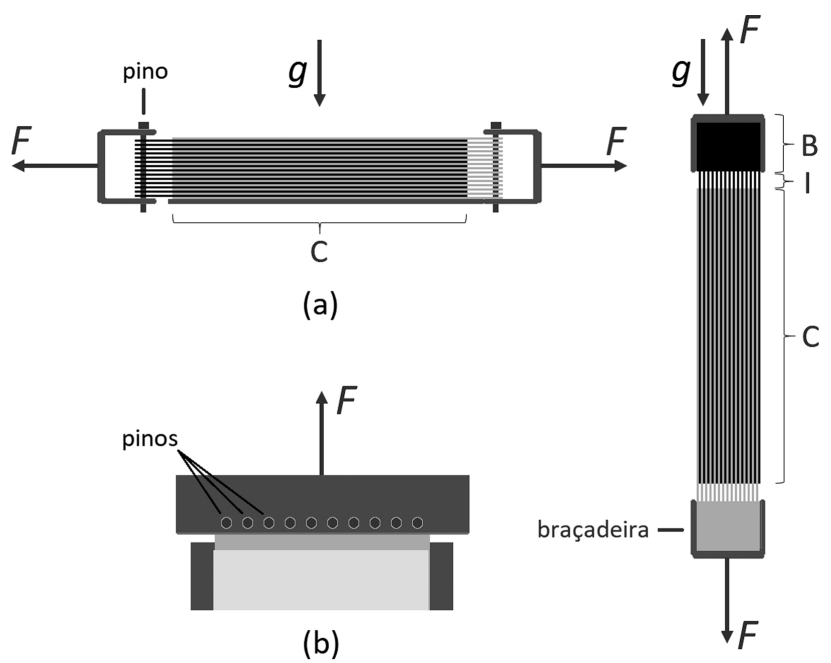

(c)

Figura 3: (a) llustração de dois grupos de folhas intercaladas, em repouso, cada grupo sendo puxado horizontalmente com força de módulo $F$, através de um total de 20 pinos (10 para cada grupo). A região $C$ é a região de contato entre as folhas dos dois grupos. (b) Vista superior da parte esquerda da Fig.3p. (c) Modificação feita por Alarcón e colaboradores em sua montagem, com a retirada de folhas, de forma alternada, dos dois grupos ilustrados na Fig.1. para mostrar que nessa configuração - não havendo o efeito de amplificação do atrito, e sendo as forças aplicadas verticalmente - os dois grupos de folhas são facilmente separados. As regiões $B, I$ e $C$ são, respectivamente, as regiões da Braçadeira, Intermediária e de Contato (para o grupo superior). Em a e c está indicada a direção do vetor aceleração da gravidade.

obtidos por Alarcón de colaboradores [6], e, como você verá, os resultados são surpreendentes.

Por que os autores do PRL [6] não relataram a dificuldade de se separar dois conjuntos de folhas na configuração apresentada na Fig. 3 a - ou seja, sem o efeito de amplificação do atrito, mas com as folhas sendo pressionadas umas contra as outras pela ação exclusiva da gravidade -, não sabemos. Talvez não tenham realizado o experimento naquela configuração. Ou talvez tenham desejado discutir apenas o efeito de amplificação do atrito. Mas, associado a essa questão, há algo curioso naquele estudo: os pesquisadores fizeram uma modificação em sua montagem (indicada aqui na Fig. 3r), com a retirada de folhas, de forma alternada, dos dois grupos ilustrados na Fig.1 para mostrar que nessa configuração os dois grupos de folhas são facilmente separados. Não há surpresa nisso, pois em tal configuração não ocorre nem a amplificação do atrito, nem a ação da gravidade pressionando as folhas umas contra as outras, restando apenas pequenas forças de adesão entre folhas adjacentes. Para examinar o efeito da gravidade, os pesquisadores teriam que ter girado de 90 graus todo o aparato ilustrado na Fig.3. (obtendo algo equivalente ao que é apresentado na Fig. 3a), mas, aparentemente, não o fizeram. Ou seja, não trabalharam com nenhuma configuração que permitisse a investigação do efeito exclusivo da gravidade - ou, se trabalharam, não consideraram importante relatar. Mas,

em defesa dos autores do PRL, devemos dizer que o problema modificado apresentado na Fig. 3a não constitui o problema da dificuldade de se separar duas listas telefônicas com suas folhas intercaladas, pois nas listas há as lombadas (fazendo o papel das braçadeiras na Fig.1), que inevitavelmente levam ao fenômeno de amplificação do atrito (se nenhuma folha é retirada). Mesmo assim, como veremos, e já anunciamos, a investigação desse problema modificado é bastante interessante, e, nele, a gravidade desemprenha um papel fundamental.

Por fim, na seção 5 apresentaremos as conclusões deste trabalho.

\section{O modelo de Alarcón e colaboradores}

Modelagem, em física, necessariamente envolve algum tipo de simplificação do sistema físico investigado (ou seja, modelado) 9 No modelo de Alarcón e colaboradores [6], a simplificação começa pela conformação de cada folha das duas listas telefônicas intercaladas: como indicado na Fig. 4. cada folha da lista da esquerda é perfeitamente plana em cada uma das regiões $B, I$ e $C$; com isso, as conexões entre as partes B e I e entre as partes I e C formam ângulos - ou seja, não há curvas nas folhas de papel. (As folhas da lista da direita são modeladas de modo equivalente.) Trata-se realmente de uma simplificação, sobretudo com relação à disposição das folhas nas regiões I e C (observe, por exemplo, a figura 1 do artigo publicado na Physics Today [13], ou os vídeos nas referências 1, 2, 4 e 5; a Fig. 1] aqui, é um pouco mais representativa da conformação das folhas em uma situação real, embora ainda apresente uma simetria que dificilmente é obtida

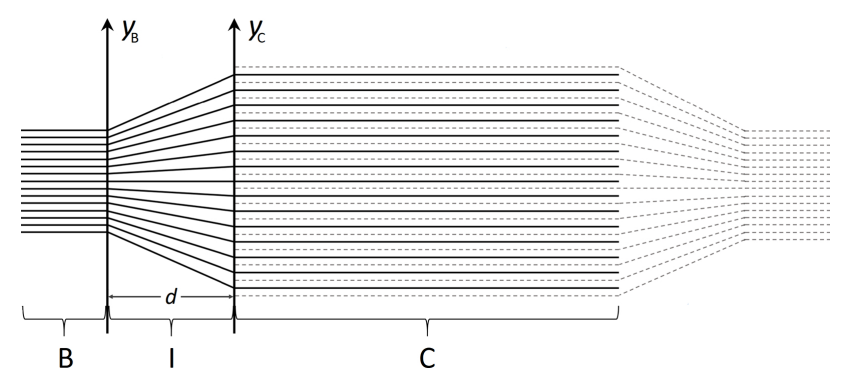

Figura 4: Disposição das folhas intercaladas de duas listas telefônicas, segundo o modelo de Alarcón e colaboradores [6]. Neste exemplo, há 15 folhas (linhas cheias) na lista da esquerda e 16 folhas (linhas tracejadas) na lista da direita. (Trabalharemos sempre com um número $N$ ímpar de folhas no grupo da esquerda, e com $N+1$ folhas no grupo da direita.) O espaçamento entre as folhas foi introduzido apenas para facilitar a visualização, e, obviamente, não deve ser considerado nos cálculos. As regiões $B$, I e C são as mesmas indicadas na Fig. 1. e as variáveis $y_{\mathrm{B}}$ e $y_{\mathrm{C}}$ serão usadas, aqui, para a especificação das posições das bases das folhas da esquerda nas regiões $B$ e $C$, respectivamente, a partir $d a$ base da folha central. $d$ é a largura da zona intermediária.

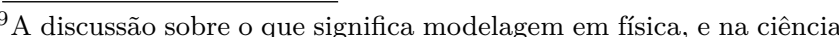
em geral, está longe de ser algo trivial. Veja, por exemplo, o texto do professor de filosofia Roman Frigg, na Routledge Encyclopedia of Philosophy Online 20].
} 
na prática). Além disso, como as folhas em cada lista têm o mesmo tamanho, a fronteira entre as regiões I e C não poderia ser perfeitamente plana; mas esta simplificação adicional nos permite trabalhar com uma largura única $d$ característica da zona intermediária (veja a Fig. 4). Consideraremos sempre um número ímpar de folhas na lista da esquerda, e, como sugere a Fig. 4 a folha central daquela lista terá sempre uma direção única nas regiões B, I e C. Com isso, obteremos simetria no cálculo das forças que atuam sobre as folhas da lista da esquerda, de modo que poderemos considerar, explicitamente, apenas sua metade superior, além de sua folha central.

A especificação da conformação de cada folha da lista da esquerda, da região da braçadeira à zona de contato, é essencial para a análise das forças que atuam nas mesmas em cada uma das regiões B, I e C. Considerar plana cada folha em cada uma daquelas regiões simplifica enormemente o trabalho. Em particular, nos interessa o ângulo formado na região intermediária por cada folha da lista da esquerda, com relação à direção da folha central. Usando a variável $n$ para a numeração das folhas da lista da esquerda, a partir da folha central (folha $n=0$ ), e as variáveis $y_{\mathrm{B}}$ e $y_{\mathrm{C}}$ para a especificação das posições das bases daquelas folhas nas regiões $\mathrm{B}$ e $\mathrm{C}$, respectivamente, a partir da base da folha central, e sendo $\epsilon$ a espessura de cada folha, obtemos (veja a Fig.5 $y_{\mathrm{B}}(n)=n \epsilon$ e $y_{\mathrm{C}}(n)=2 n \epsilon$. Ou seja, essas são as posições da base da folha $n$, a partir da base da folha central, respectivamente na região da braçadeira e na zona de contato. A diferença $y_{\mathrm{C}}(n)-y_{\mathrm{B}}(n)=n \epsilon$ nos dá a elevação da folha $n$ da região $\mathrm{B}$ à região $\mathrm{C}$, e o ângulo $\theta_{n}$ formado pela mesma na região intermediária, com relação à direção da folha central, satisfaz (como mostra a Fig. 5p) a relação

$$
\operatorname{tg} \theta_{n}=\frac{n \epsilon}{d}
$$

com $n \in\{0,1,2, \ldots,(N-1) / 2\}$, sendo $N$ o número total de folhas na lista da esquerda (lembre-se de que trabalharemos sempre com $N$ ímpar, e que o número total de folhas na lista da direita será sempre $N+1$ ).

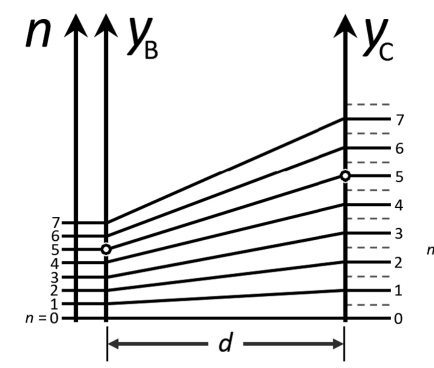

(a)

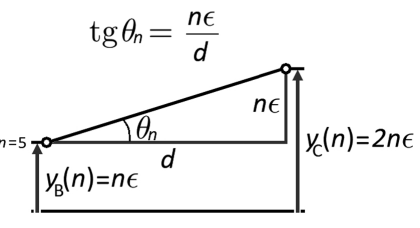

(b)
Figura 5: (a) Recorte da Fig.4. A variável $n$ é usada para a numeração das folhas, a partir da folha central do grupo da esquerda (folha $n=0$ ). As variáveis $y_{\mathrm{B}}$ e $y_{\mathrm{C}}$ estão descritas na legenda da Fig.4 (b) Cálculo do ângulo $\theta_{n}$ formado pela folha número $n$, na região intermediária, com relação à direção da folha central. Cada folha tem espessura $\epsilon$.
Faremos a seguir a análise de todas as forças que atuam na folha $n$ da lista da esquerda $(n \geq 0)$, nas regiões I e $\mathrm{C}$, e das forças relevantes (para o modelo) que atuam na mesma folha, na região B. Em nossa experiência de pensamento, o grupo de folhas da direita será fixado a uma superfície, através de sua braçadeira, e puxaremos para a esquerda, com força de módulo $F$, a braçadeira da esquerda e o grupo de folhas da esquerda (como ilustrado na Fig. 11. 10

Iniciemos pela parte da folha $n$ na região intermediária. Observe, por exemplo, a folha $n=5$ na Fig. 5 . Devido à separação entre as folhas $n$ e $n-1$ e entre as folhas $n$ e $n+1$ em toda a zona intermediária, causada pela intercalação daquelas folhas com folhas do grupo da direita na zona de contato, as forças que agem sobre a parte da folha $n$ situada na região I atuam apenas em suas extremidades. E, além disso, essas forças têm a mesma direção da folha na região I, como ilustra a Fig.6p; do contrário, aquela parte da folha não estaria em equilíbrio. É claro, cada uma das forças na Fig. 6a corresponde a uma soma de forças atuando ao londo de toda a fronteira da região I com a região $\mathrm{B}$ ou $\mathrm{C}$.

A Fig.6p ilustra a "reação" (no sentido da terceira lei de Newton) à força de módulo $T_{n}$ à esquerda na Fig. 6a, aplicada sobre a parte da folha $n$ situada na região da

(a)

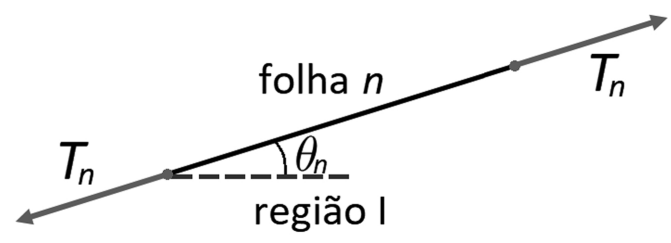

(b)

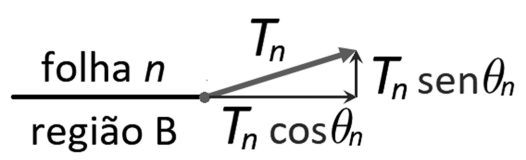

(c)

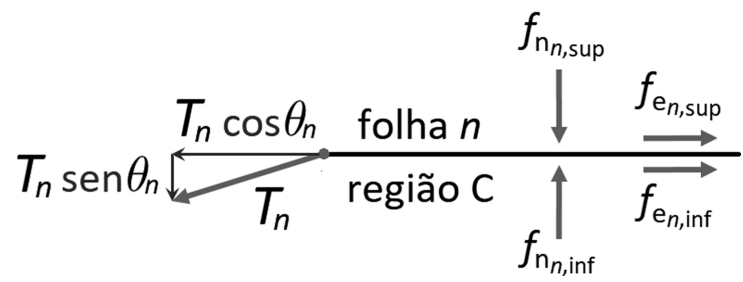

Figura 6: (a) Forças atuando sobre a parte da folha $n$ (da lista da esquerda) situada na zona intermediária. (b) Força sobre a parte da folha $n$ situada na região da braçadeira, aplicada pela parte da mesma folha na região I. (c) Força sobre a parte da folha $n$ situada na zona de contato, aplicada pela parte da mesma folha na região I, e forças normais e de atrito estático aplicadas à folha $n$ pelas folhas adjacentes superior e inferior (ambas da lista da direita).

${ }^{10}$ Comentamos na seção[1] que Alarcón e colaboradores realizaram seu experimento sempre na direção vertical, e, portanto, teríamos aqui uma representação daquele experimento em princípio mais adequada com as Figs.1 4 e 5 giradas de 90 graus (no sentido horário); mas no próprio PRL [6] há (na figura 1b daquele artigo) um esquema semelhante ao apresentado aqui nas Figs. 4 e 5 - ou seja, como se as listas estivessem sendo puxadas horizontalmente. 
braçadeira, além de sua decomposição em duas direções ortogonais entre si. Analogamente, a Fig. 6. ilustra a "reação", aplicada sobre a parte da folha $n$ situada na zona de contato, à força de módulo $T_{n}$ à direita na Fig. 6a, e também sua decomposição em duas direções ortogonais. Estão ainda ilustradas na Fig.6. as forças normais $f_{\mathrm{n}_{n, \text { sup }}}$ e $f_{\mathrm{n}_{n, \text { inf }}}$ e as forças de atrito estático $f_{\mathrm{e}_{n, \text { sup }}}$ e $f_{\mathrm{e}_{n, \text { inf }}}$, aplicadas à folha $n$ da lista da esquerda respectivamente pelas folhas adjacentes superior e inferior (ambas da lista da direita).

O equilíbrio da parte da folha $n$ situada na zona de contato envolve a seguinte igualdade (veja a Fig.66):

$$
T_{n} \cos \theta_{n}=f_{\mathrm{e}_{n, \text { sup }}}+f_{\mathrm{e}_{n, \text { inf }}} .
$$

Consideremos agora que a lista da esquerda está na iminência de movimento em relação à lista da direita. (Com isso, é claro, estamos supondo que a separação entre as listas é possível.) Neste caso, temos, de acordo com as leis clássicas de atrito (veja a Fig.66):

$$
f_{\mathrm{e}_{n, \text { sup }}}=f_{\mathrm{e}_{n}, \text { sup }}^{\max }=\mu_{\mathrm{e}} f_{\mathrm{n}_{n, \text { sup }}}
$$

e

$$
f_{\mathrm{e}_{n, \text { inf }}}=f_{\mathrm{e}_{n, \text { inf }}}^{\max }=\mu_{\mathrm{e}} f_{\mathrm{n}_{n, \text { inf }}},
$$

em que $\mu_{\mathrm{e}}$ é o coeficiente de atrito estático entre as folhas de papel.

Para calcularmos $f_{\mathrm{n}_{n, \text { inf }}}$, consideraremos o bloco da zona de contato constituído pela folha $n$ da lista da esquerda e por todas as folhas acima dela (das listas da esquerda e da direita), e aplicaremos a esse bloco, que está em repouso, a segunda lei de Newton.

Pois bem, o módulo da força total que empurra o bloco para cima é $f_{\mathrm{n}_{n, \text { inf }}}$. Para obtermos o módulo da força total que empurra o bloco para baixo, observemos primeiramente que a contribuição das forças exercidas através das folhas da lista da esquerda é (veja a Fig. 6c) $\sum_{k=n}^{(N-1) / 2} T_{k} \operatorname{sen} \theta_{k}$. Para encontrarmos a contribuição das forças exercidas através das folhas da lista da direita, precisaremos introduzir novas variáveis no problema.

Usaremos a variável $\tilde{n}$ para numerar as folhas da metade superior da lista da direita: a primeira folha da metade superior é a folha $\tilde{n}=1$, e a última (a folha externa) é a folha $\tilde{n}=(N+1) / 2$.

As grandezas $\tilde{\theta}_{\tilde{n}}$ e $\tilde{T}_{\tilde{n}}$ têm definições, para a folha $\tilde{n}$ da lista da direita, correspondentes às definições de $\theta_{n}$ e $T_{n}$ para a folha $n$ da lista da esquerda. Ou seja, $\tilde{\theta}_{\tilde{n}}$ é o ângulo (agudo) formado pela folha $\tilde{n}$ da lista da direita com relação à direção da folha central da lista da esquerda, e $\tilde{T}_{\tilde{n}}$ é o módulo da força resultante em cada uma das duas extremidades da parte da folha $\tilde{n}$ da lista da direita, na zona intermediária, que faz fronteira com a zona de contato ou com a região da braçadeira.

Deixaremos para você a tarefa de obter, à semelhança da construção apresentada na Fig. 5 .

$$
\operatorname{tg} \tilde{\theta}_{\tilde{n}}=\frac{(\tilde{n}-1 / 2) \epsilon}{d}
$$

em que $d$ é também a largura da zona intermediária da lista da direita.
Observando a Fig. 4, podemos concluir que a contribuição das forças exercidas através das folhas da lista da direita, para o módulo da força total que empurra para baixo o bloco acima descrito, é $\sum_{\tilde{k}=n+1}^{(N+1) / 2} \tilde{T}_{\tilde{k}} \operatorname{sen} \tilde{\theta}_{\tilde{k}}$.

Temos, então:

$$
f_{\mathrm{n}_{n}, \mathrm{inf}}=\sum_{k=n}^{(N-1) / 2} T_{k} \operatorname{sen} \theta_{k}+\sum_{\tilde{k}=n+1}^{(N+1) / 2} \tilde{T}_{\tilde{k}} \operatorname{sen} \tilde{\theta}_{\tilde{k}} .
$$

Para calcularmos $f_{\mathrm{n}_{n, \text { sup }}}$, observemos que, de acordo com a terceira lei de Newton, este é o módulo da força com que a folha $n$ da lista da esquerda empurra para cima a folha superior, da lista da direita. Podemos então considerar o bloco da zona de contato constituído por todas as folhas (das duas listas) acima da folha $n$ da lista da esquerda. Aplicando a esse bloco a segunda lei de Newton, obtemos:

$$
f_{\mathrm{n}_{n, \text { sup }}}=\sum_{\substack{k=n+1 \\(n<(N-1) / 2)}}^{(N-1) / 2} T_{k} \operatorname{sen} \theta_{k}+\sum_{\tilde{k}=n+1}^{(N+1) / 2} \tilde{T}_{\tilde{k}} \operatorname{sen} \tilde{\theta}_{\tilde{k}}
$$

Perceba que há duas diferenças entre as expressões no segundo membro de (6) e no segundo membro de (7): uma está no primeiro valor assumido por $k(n$ e $n+1$, respectivamente), e a outra está no fato de que não podemos fazer $n=(N-1) / 2$ no primeiro somatório em 77) (e daí a condição $n<(N-1) / 2$ lá expressa), pois a última folha da lista da esquerda é a folha $(N-1) / 2$, e, portanto, não existe a folha $n+1$ para $n=(N-1) / 2$.

Concluímos nossa análise de forças sobre cada uma das três partes (B, I e C) das folhas da lista da esquerda. No processo, obtivemos expressões que envolvem quantidades associadas às folhas da lista da direita (veja as igualdades (5), (6) e (7) ). O que fazer com os resultados (1) a (7) obtidos? É o que discutiremos a seguir.

Consideremos o bloco constituído por todas as folhas da lista da esquerda na região da braçadeira, e pela própria braçadeira. Lembre-se de que estamos considerando que a lista da esquerda está na iminência de movimento em relação à lista da direita. Aplicando a esse bloco a segunda lei de Newton, e sendo $F_{\text {crítica }}$ o valor de $F$ nessa situação, obtemos (veja as Figs.11e 6p):

$$
F_{\text {crítica }}=T_{0} \cos \theta_{0}+2 \sum_{n=1}^{(N-1) / 2} T_{n} \cos \theta_{n}
$$

O alvo do modelo de Alarcón e colaboradores é a obtenção de uma expressão para $F_{\text {crítica }}$ em função de parâmetros mensuráveis do sistema ( $\mu_{\mathrm{e}}, \epsilon, N$ e d), fazendo uso do que foi obtido nesta seção até aqui (igualdades (1) a (8)). Mas, como veremos, não se trata de uma tarefa trivial.

Será interessante definirmos

$$
\mathcal{F}_{n} \equiv T_{n} \cos \theta_{n}
$$

$n \in\{0,1,2, \ldots,(N-1) / 2\}$. E, analogamente,

$$
\tilde{\mathcal{F}}_{\tilde{n}} \equiv \tilde{T}_{\tilde{n}} \cos \tilde{\theta}_{\tilde{n}}
$$


$\tilde{n} \in\{1,2, \ldots,(N+1) / 2\}$.

Podemos então reescrever a igualdade (8) como

$$
F_{\text {critica }}=\mathcal{F}_{0}+2 \sum_{n=1}^{(N-1) / 2} \mathcal{F}_{n}
$$

O caminho natural seria usarmos as igualdades (1) a (11) para obtermos uma expressão para $F_{\text {crítica }}$. Contudo, como você pode verificar no Material Suplementar, disponível online, trabalhando com aquelas 11 igualdades chegamos à equação

$$
\begin{aligned}
& \frac{d}{2 \mu_{\mathrm{e}} \epsilon} F_{\text {crítica }}=2 \sum_{k=1}^{(N-1) / 2} k \mathcal{F}_{k}+\sum_{\tilde{k}=1}^{(N+1) / 2}(\tilde{k}-1 / 2) \tilde{\mathcal{F}}_{\tilde{k}} \\
& +2 \sum_{n=1}^{(N-1) / 2}\left(\sum_{\substack{k=n+1 \\
(<<(N-1) / 2)}}^{(N-1) / 2} k \mathcal{F}_{k}+\sum_{\tilde{k}=n+1}^{(N+1) / 2}(\tilde{k}-1 / 2) \tilde{\mathcal{F}}_{\tilde{k}}\right),
\end{aligned}
$$

que é, certamente, frustrante. Para obtermos $F_{\text {critica }}$ a partir da igualdade acima, precisamos conhecer $\mathcal{F}_{k}$ e $\tilde{\mathcal{F}}_{\tilde{k}}$, $\operatorname{com} k=1,2, \ldots,(N-1) / 2$ e $\tilde{k}=1,2, \ldots,(N+1) / 2$. Mas se conhecêssemos essas quantidades (e $\left.\mathcal{F}_{0}\right)$, usaríamos a igualdade (11) para o cálculo de $F_{\text {crítica }}$. Veremos então como os autores do PRL [6] obtiveram uma expressão para $F_{\text {crítica }}$ a partir de igualdades equivalentes às igualdades (1) a (7). Se você é um estudante ainda na primeira metade de seu curso de graduação, é muito provável que o desenvolvimento que verá a seguir seja uma novidade. Esperamos que aprecie.

Basicamente, a estratégia usada por Alarcón e colaboradores para a obtenção de uma expressão para $F_{\text {crítica }}$ a partir de igualdades equivalentes às igualdades (1) a (7) consistiu na obtenção e resolução de uma equação diferencial ordinária. Uma equação envolvendo que função? E que variável independente? Veremos. Obviamente, teremos que transformar um problema com variáveis discretas (como $n$ e $\tilde{n}$ ) em um problema envolvendo variáveis contínuas. Vamos por partes.

Primeiro, usando a definição apresentada em (9), vamos calcular a diferença

$$
\Delta \mathcal{F}_{n} \equiv \mathcal{F}_{n+1}-\mathcal{F}_{n} \quad(n<(N-1) / 2) .
$$

Substituindo (9) em (13), obtemos:

$$
\Delta \mathcal{F}_{n}=T_{n+1} \cos \theta_{n+1}-T_{n} \cos \theta_{n} .
$$

Substituindo (2) em (14), obtemos:

$$
\Delta \mathcal{F}_{n}=f_{\mathrm{e}_{n+1, \text { sup }}}+f_{\mathrm{e}_{n+1, \text { inf }}}-\left(f_{\mathrm{e}_{n, \text { sup }}}+f_{\mathrm{e}_{n, \text { inf }}}\right) .
$$

Agora, usando (3) e (4) em (15), obtemos:

$$
\Delta \mathcal{F}_{n}=\mu_{\mathrm{e}}\left(f_{\mathrm{n}_{n+1, \text { sup }}}+f_{\mathrm{n}_{n+1, \text { inf }}}-f_{\mathrm{n}_{n, \text { sup }}}-f_{\mathrm{n}_{n, \text { inf }}}\right) .
$$

Nas igualdades (14) a (16) temos a condição $n<(N-$ 1) $/ 2$, expressa na igualdade (13). Observando isto, e substituindo (6) e (7) em (16), obtemos:

$$
\begin{aligned}
& \frac{1}{\mu_{\mathrm{e}}} \Delta \mathcal{F}_{n}= \\
& \sum_{\substack{k=(n+1)+1 \\
((n+1)<(N-1) / 2)}}^{(N-1) / 2} T_{k} \operatorname{sen} \theta_{k}+\sum_{\tilde{k}=(n+1)+1}^{(N+1) / 2} \tilde{T}_{\tilde{k}} \operatorname{sen} \tilde{\theta}_{\tilde{k}} \\
& +\sum_{k=n+1}^{(N-1) / 2} T_{k} \operatorname{sen} \theta_{k}+\sum_{\tilde{k}=(n+1)+1}^{(N+1) / 2} \tilde{T}_{\tilde{k}} \operatorname{sen} \tilde{\theta}_{\tilde{k}} \\
& -\sum_{\substack{k=n+1 \\
(n<(N-1) / 2)}}^{(N-1) / 2} T_{k} \operatorname{sen} \theta_{k}-\sum_{\tilde{k}=n+1}^{(N+1) / 2} \tilde{T}_{\tilde{k}} \operatorname{sen} \tilde{\theta}_{\tilde{k}} \\
& -\sum_{k=n}^{(N-1) / 2} T_{k} \operatorname{sen} \theta_{k}-\sum_{\tilde{k}=n+1}^{(N+1) / 2} \tilde{T}_{\tilde{k}} \operatorname{sen} \tilde{\theta}_{\tilde{k}},
\end{aligned}
$$

com $n<(N-1) / 2$.

Podemos simplificar este resultado. Trabalharemos com $n<(N-1) / 2-1$ (ou, equivalentemente, $\operatorname{com} n_{\text {máximo }}=$ $(N-1) / 2-2)$, de modo que teremos sempre todos os oito somatórios em (17). (Não devemos nos preocupar com essa restrição, pois transformaremos o problema discreto que temos em mãos em um problema envolvendo variáveis contínuas, e aplicaremos a ele as devidas condições de contorno.) Pois bem, em primeiro lugar, perceba que os somatórios 3 e 5 se cancelam. Agora, observe que os valores assumidos por $k$ no primeiro somatório são os inteiros $n+2$ a $(N-1) / 2$, enquanto os valores assumidos por $k$ no sétimo somatório são os inteiros $n$ a $(N-$ 1)/2. Portanto, o somatório 7 contém todos os termos do somatório 1, e dois termos extras: os termos $k=n \mathrm{e}$ $k=n+1$. Então a diferença entre o primeiro e o sétimo somatórios é:

$$
-T_{n} \operatorname{sen} \theta_{n}-T_{n+1} \operatorname{sen} \theta_{n+1} .
$$

Agora, passemos aos somatórios 2, 4, 6 e 8. Nos somatórios 2 e 4 (que são iguais), os valores assumidos por $\tilde{k}$ são $n+2$ a $(N+1) / 2$, enquanto os valores assumidos por $\tilde{k}$ nos somatórios 6 e 8 (também iguais entre si) são $n+1$ a $(N+1) / 2$. Logo, é fácil ver que desses quatro somatórios resulta a quantidade

$$
-2 \tilde{T}_{n+1} \operatorname{sen} \tilde{\theta}_{n+1} \text {. }
$$

Portanto, podemos reescrever a igualdade (17) como:

$$
\begin{aligned}
\frac{1}{\mu_{\mathrm{e}}} \Delta \mathcal{F}_{n}= & -T_{n} \operatorname{sen} \theta_{n}-T_{n+1} \operatorname{sen} \theta_{n+1} \\
& -2 \tilde{T}_{n+1} \operatorname{sen} \tilde{\theta}_{n+1},
\end{aligned}
$$

com $n<(N-1) / 2-1$.

Multiplicando, acima, $\operatorname{sen} \theta_{n}$ por $\cos \theta_{n} / \cos \theta_{n}, \operatorname{sen} \theta_{n+1}$ por $\cos \theta_{n+1} / \cos \theta_{n+1}$, e $\operatorname{sen} \tilde{\theta}_{n+1}$ por $\cos \tilde{\theta}_{n+1} / \cos \tilde{\theta}_{n+1}$, e usando as igualdades (1), (5), (9) e (10), obtemos:

$$
\begin{aligned}
\frac{1}{\mu_{\mathrm{e}}} \Delta \mathcal{F}_{n}= & -\frac{n \epsilon}{d} \mathcal{F}_{n}-\frac{(n+1) \epsilon}{d} \mathcal{F}_{n+1} \\
& -2 \frac{(n+1-1 / 2) \epsilon}{d} \tilde{\mathcal{F}}_{n+1},
\end{aligned}
$$


com $n<(N-1) / 2-1$.

No desenvolvimento de seu modelo, Alarcón e colaboradores consideraram $N \gg 1$; ou seja, consideraram que o número total de folhas em cada uma das duas listas é muito maior que 1 - que é o caso, obviamente, quando se trata de listas telefônicas reais. Contudo, nos experimentos que realizaram 6], Alarcón e colaboradores trabalharam com $N=24,30,46,54,100,150$ e 200. Mas mesmo para um valor de $N$ relativamente pequeno como $N=24$ (ou $N=23$, já que estamos considerando, aqui, que a lista da esquerda possui sempre um número ímpar de folhas), parece-nos razoável considerar

$$
\tilde{\mathcal{F}}_{n+1} \approx \mathcal{F}_{n+1} \approx \mathcal{F}_{n}
$$

Observe a Fig. 4. Nela, a lista da esquerda só tem 15 folhas (e a da direita, 16), e, mesmo sendo esse um número ainda menor, parecem-nos razoáveis as aproximações acima.11 Com elas, podemos reescrever a relação 19 como:

$$
\Delta \mathcal{F}_{n} \approx-2(2 n+1) \frac{\mu_{\mathrm{e}} \epsilon}{d} \mathcal{F}_{n}
$$

com $n<(N-1) / 2-1$.

Para $1 \ll n<(N-1) / 2-1$ temos $2 n+1 \approx 2 n$, e com isso obtemos uma expressão ainda mais simples para $\Delta \mathcal{F}_{n}:$

$$
\Delta \mathcal{F}_{n} \approx-\frac{4 \mu_{\mathrm{e}} \epsilon}{d} n \mathcal{F}_{n}
$$

com $1 \ll n<(N-1) / 2-1.12$

Com a aproximação em 21), concluímos uma importante etapa do desenvolvimento do modelo de Alarcón e colaboradores. Veremos agora como obter uma equação diferencial a partir da relação 21.

Iniciaremos introduzindo uma nova variável: $z \equiv$ $n / n_{\text {máximo }}, \operatorname{com} n_{\text {máximo }}=(N-1) / 2-2$ e $1 \ll n \leq$ $n_{\text {máximo }}$, que é o intervalo de $n$ para o qual é válida a aproximação em (21). Trabalhando com $z$, em vez de $n$, poderíamos usar a notação $\mathcal{F}_{z}$. Mas como temos em vista a obtenção de uma equação diferencial, usaremos a notação padrão para funções no Cálculo: $\mathcal{F}(z)$. Assim, para um dado $n$ satisfazendo $1 \ll n \leq n_{\text {máximo }}=(N-1) / 2-2$, temos $z=n / n_{\text {máximo }}$ e $\mathcal{F}(z)=\overline{\mathcal{F}}_{n}$. Por enquanto, $z$ é uma variável discreta (como $n$ ), mas com valores no intervalo de 0 a 1 (enquanto $n$ assume apenas valores inteiros). Entenda que o valor de $z$ especifica a posição de uma folha da lista da esquerda, mas agora medida em uma nova escala.

Como a relação $1 \ll n \leq n_{\text {máximo }}$ só é válida, é claro, para $n_{\text {máximo }} \gg 1$, e, portanto, para $N \gg 1$, podemos

\footnotetext{
${ }^{11}$ Estamos, aqui, apelando para a sua intuição física. Perceba, por exemplo, como é ínfima na Fig. 4 a diferença entre os ângulos $\theta_{n}$ e $\theta_{n+1}$, para um $n$ qualquer; e olha que o espaçamento entre as folhas, introduzido na Fig. 4 apenas para facilitar a visualização, nem deve ser considerado! Note também como a assimetria entre as listas da esquerda e da direita, por ser pequena, não deve resultar em uma diferença significativa entre $\tilde{\mathcal{F}}_{n+1}$ e $\mathcal{F}_{n+1}$ (lembre-se de que a lista da direita só tem uma folha a mais que a da esquerda). ${ }^{12} \mathrm{~A}$ aproximação em 21 corresponde à igualdade (1) do artigo de Alarcón e colaboradores [6], deduzida como uma aproximação no Material Suplementar daquele artigo.
}

aproximar: $n_{\text {máximo }} \approx N / 2$. Assim, em termos da variável $z$, podemos reescrever a relação (21) como:

$$
\Delta \mathcal{F}(z) \approx-\frac{2 \mu_{\mathrm{e}} \epsilon N}{d} z \mathcal{F}(z)
$$

$\operatorname{com} z \equiv n / n_{\text {máximo }} \approx 2 n / N$ e $1 \ll n \leq n_{\text {máximo }}$.

Agora, observe que à variação $\Delta \overline{\mathcal{F}}(z)=\Delta \mathcal{F}_{n}$ corresponde a variação $\Delta n=(n+1)-n=1$ (veja a definição em (13)), e à variação $\Delta n=1$ corresponde a variação $\Delta z=(2 / N) \Delta n=2 / N$. Portanto, dividindo ambos os membros de 22 por $\Delta z=2 / N$, obtemos:

$$
\frac{\Delta \mathcal{F}(z)}{\Delta z} \approx-\frac{\mu_{\mathrm{e}} \epsilon N^{2}}{d} z \mathcal{F}(z),
$$

$\operatorname{com} z \equiv n / n_{\text {máximo }} \approx 2 n / N$ e $1 \ll n \leq n_{\text {máximo. }}$. Mudaremos esta faixa de valores para $n$ logo adiante.)

Se conseguíssemos encontrar uma função $\mathcal{F}(z)$ para todo $z$ de interesse (ou, equivalentemente, se conseguíssemos encontrar uma função $\mathcal{F}_{n}$ para todo $n$ de interesse), então através da igualdade (11) calcularíamos a força $F_{\text {crítica }}$ necessária para por a lista da esquerda na iminência de movimento. Lembre-se de que é isso o que estamos buscando. O que temos em mãos é a relação (23).

Um primeiro problema é que a relação não tem validade para todo $z$ de interesse, mas para $z=n / n_{\text {máximo }} \approx$ $2 n / N$, com $1 \ll n \leq n_{\text {máximo. }}$ Ou seja, aquela aproximação não é boa para as folhas da lista da esquerda mais próximas da folha central (a folha $n=0$ ). Mas isso não é algo grave, se tivermos em mente um valor de $N$ grande o suficiente para que alcancemos $n \gg 1$ (no sentido de que $2 n+1 \approx 2 n$ ) após uma pequena fração do conjunto total de folhas, de modo que possamos aplicar a relação (23) a todas as folhas da lista da esquerda (ou, mais precisamente, a todas as folhas de sua metade superior) sem incorrermos em grande erro. Observe, revendo o trecho entre as igualdades $(19)$ e 22, , que as aproximações introduzidas (entre elas a aproximação $2 n+1 \approx 2 n$ ) são relativamente boas (diferenças relativas não superiores a $10 \%$ ) para valores tão baixos quanto $N=55$ e $n=5$, e neste caso temos $n / n_{\text {máximo }}=2 n / N \approx 0,18$. Então, $a$ partir daqui, aplicaremos a aproximação em (23) a todas as folhas da metade superior da lista da esquerda (mas, preferencialmente, mantendo $N \gtrsim 5 5 \longdiv { 1 3 }$ Ou seja, trabalharemos com $z \equiv n / n_{\text {máximo }} \approx 2 n / N, 0 \leq n \leq n_{\text {máximo }} e$ $N \gg 1$ (preferencialmente $N \gtrsim 55$ ). Note que temos, então, $0 \leq z \leq 1$, e que o número de valores que a variável $z$ pode assumir neste intervalo é aproximadamente $N / 2$.

Mas como obtermos uma função $\mathcal{F}(z)$ que satisfaça a relação 23)? Bem, essa tarefa não seria difícil se, em (23), $z$ fosse uma variável contínua e no membro esquerdo tivéssemos uma derivada; tratar-se-ia da resolução de uma equação diferencial trivial. Contudo, você não deve se deixar seduzir por essa ideia tão rapidamente. Vamos analisá-la com cuidado.

Podemos tornar z uma variável contínua no intervalo $[0,1]$, mas tendo em mente que $\mathcal{F}(z)$ só terá significado

\footnotetext{
13 Lembre-se de que Alarcón e colaboradores trabalharam, em seu experimento, com $N=24,30,46,54,100,150$ e 200 . No desenvolvimento apresentado não temos aproximações muito boas para valores como $N=24$ e $N=30$ (ou seus vizinhos ímpares).
} 
físico para um conjunto discreto de valores de z: aqueles correspondentes à aproximação em $(23)\left(z=n / n_{\text {máximo }} \approx\right.$ $2 n / N$, com $0 \leq n \leq n_{\text {máximo }}$ e $\left.N \gg 1(N \gtrsim 55)\right)$. Como para $N \gg 1$ temos $\Delta z=2 / N \ll 1$, podemos encarar o membro esquerdo da relação (23) como uma ótima aproximação para a derivada de $\mathcal{F}(z)$ (sendo $z$ agora uma variável contínua). Temos então a seguinte equação diferencial:

$$
\frac{\mathrm{d} \mathcal{F}(z)}{\mathrm{d} z}=-\frac{\mu_{\mathrm{e}} \epsilon N^{2}}{d} z \mathcal{F}(z) .
$$

A resolução desta equação diferencial, pelo método de separação de variáveis, é trivial. Vamos inicialmente reescrevê-la como

$$
\frac{\mathrm{d} \mathcal{F}}{\mathcal{F}}=-\frac{\mu_{\mathrm{e}} \epsilon N^{2}}{d} z \mathrm{~d} z .
$$

Integrando, com $0 \leq z \leq 1$, obtemos:

$$
\begin{gathered}
\int_{\mathcal{F}(z)}^{\mathcal{F}(1)} \frac{\mathrm{d} \mathcal{F}^{\prime}}{\mathcal{F}^{\prime}}=-\frac{\mu_{\mathrm{e}} \epsilon N^{2}}{d} \int_{z}^{1} z^{\prime} \mathrm{d} z^{\prime} \Longrightarrow \\
\ln \frac{\mathcal{F}(1)}{\mathcal{F}(z)}=-\frac{\mu_{\mathrm{e}} \epsilon N^{2}}{2 d}\left(1-z^{2}\right) \Longrightarrow \\
\mathcal{F}(z)=\mathcal{F}(1) e^{\alpha\left(1-z^{2}\right)}=\mathcal{F}(1) \frac{\exp (\alpha)}{\exp \left(\alpha z^{2}\right)},
\end{gathered}
$$

com

$$
\alpha \equiv \frac{\mu_{\mathrm{e}} \epsilon N^{2}}{2 d} .
$$

Vale lembrar, a igualdade 25 só tem significado físico para um conjunto discreto de aproximadamente $N / 2$ (ou exatamente $(N+1) / 2$ ) valores de $z$, igualmente espaçados no intervalo $[0,1]$, incluindo os extremos 0 e 1 . E o parâmetro $\alpha$ é o chamado "número de Hércules".

Qual é o significado físico de $\alpha$, em 25]? Simples: para $z=0$ obtemos $\mathcal{F}(0)=\mathcal{F}(1) e^{\alpha}$, e, portanto,

$$
\frac{\mathcal{F}(0)}{\mathcal{F}(1)}=e^{\alpha} \text {. }
$$

Ou seja, com excelente aproximação (para $N \gtrsim 55$ ), a razão entre a força total de atrito sobre a folha central da lista da esquerda e a força total de atrito sobre uma das folhas externas da mesma lista cresce exponencialmente com $\alpha$ (veja a Fig. 4 a definição em (9), a igualdade (2) e a Fig.6.). Já dá pra prever, então, um crescimento muito rápido, $\operatorname{com} \alpha$ (e, em particular, com $N$ ), do módulo $F_{\text {crítica }}$ da força necessária para por a lista da esquerda na iminência de movimento.

A etapa final do desenvolvimento do modelo de Alarcón e colaboradores consiste no cálculo de $F_{\text {crítica }}$ fazendo-se uso da expressão para $\mathcal{F}(z)$ em 25 .

Em termos de $z$, podemos reescrever a igualdade (11) como

$$
F_{\text {crítica }} \approx 2 \sum_{z} \mathcal{F}(z)
$$

com $z$ assumindo, neste somatório, os $(N+1) / 2$ valores igualmente espaçados no intervalo $[0,1]$, incluindo os extremos 0 e 1 . Considerando $N \gg 114$ podemos aproximar o somatório em 28 por uma integral, observando que

$$
\int_{0}^{1} \mathcal{F}(z) \mathrm{d} z \approx \sum_{z} \mathcal{F}(z) \Delta z
$$

com $\Delta z=2 / N{ }^{15}$ Obviamente, no membro esquerdo da relação 29 temos em $z$ uma variável contínua no intervalo $[0,1]$, enquanto no membro direito $z$ é uma variável discreta assumindo, no somatório, os $(N+1) / 2$ valores descritos acima. Combinando 28$]$ e $(29)$, obtemos (usando "=", em vez de “ح"):

$$
F_{\text {crítica }}=\frac{2}{\Delta z} \int_{0}^{1} \mathcal{F}(z) \mathrm{d} z=N \int_{0}^{1} \mathcal{F}(z) \mathrm{d} z .
$$

Tudo pronto para fazermos uso da igualdade (25). Substituindo 25 em 30, obtemos:

$$
\begin{aligned}
F_{\text {crítica }} & =N \int_{0}^{1} \mathcal{F}(1) e^{\alpha\left(1-z^{2}\right)} \mathrm{d} z \\
& =N \mathcal{F}(1) e^{\alpha} \int_{0}^{1} e^{-\alpha z^{2}} \mathrm{~d} z .
\end{aligned}
$$

Introduzindo a variável $u \equiv \sqrt{\alpha} z$, podemos reescrever:

$$
\begin{aligned}
F_{\text {crítica }} & =N \mathcal{F}(1) e^{\alpha} \int_{0}^{\sqrt{\alpha}} e^{-u^{2}} \frac{\mathrm{d} u}{\sqrt{\alpha}} \\
& =N \mathcal{F}(1) \frac{e^{\alpha}}{\sqrt{\alpha}} \int_{0}^{\sqrt{\alpha}} e^{-u^{2}} \mathrm{~d} u .
\end{aligned}
$$

Introduziremos na expressão acima para $F_{\text {crítica }}$ a função erro, definida comq ${ }^{16}$

$$
\operatorname{erf}(x) \equiv \frac{2}{\sqrt{\pi}} \int_{0}^{x} e^{-u^{2}} \mathrm{~d} u
$$

obtendo

$$
F_{\text {crítica }}=N \mathcal{F}(1) \frac{e^{\alpha}}{\sqrt{\alpha}} \frac{\sqrt{\pi}}{2} \operatorname{erf}(\sqrt{\alpha}),
$$

ou, reescrevendo,

$$
\frac{F_{\text {crítica }}}{N \mathcal{F}(1)}=\sqrt{\frac{\pi}{4 \alpha}} \exp (\alpha) \operatorname{erf}(\sqrt{\alpha}),
$$

que é o resultado final do desenvolvimento do modelo de Alarcón e colaboradores. ${ }^{17}$ (Lembre-se de que $\alpha \equiv$ $\mu_{\mathrm{e}} \epsilon N^{2} / 2 d$.)

\footnotetext{
${ }^{14}$ Conforme já justificado, devemos encarar, aqui, a relação $N \gg 1$ como $N \gtrsim 55$.

${ }^{15}$ Lembre-se de que à variação $\Delta n=1$ corresponde a variação $\Delta z=\Delta\left(\frac{n}{n_{\text {máximo }}}\right)=\frac{\Delta n}{n_{\text {máximo }}}=\frac{1}{n_{\text {máximo }}} \approx \frac{1}{N / 2}=\frac{2}{N}$.

${ }^{16} \operatorname{erf}(x)$ deve ser calculada numericamente para cada valor de $x>0$ desejado, e o fator $2 / \sqrt{\pi}$ em 32 é um fator de normalização, pois $\int_{0}^{\infty} e^{-u^{2}} \mathrm{~d} u=\sqrt{\pi} / 2$, e, portanto, $\operatorname{erf}(x) \rightarrow 1$ quando $x \rightarrow \infty$. Obviamente, $\operatorname{erf}(0)=0$. Logo, temos $0 \leq \operatorname{erf}(x)<1$, para $x \geq 0$. (A igualdade $\int_{0}^{\infty} e^{-u^{2}} \mathrm{~d} u=\sqrt{\pi} / 2$ é obtida com o uso de coordenadas polares, e o procedimento não se aplica quando o limite superior da integral é finito. Pesquise a respeito.)

${ }^{17} \mathrm{~A}$ igualdade 34 corresponde à igualdade (3) do PRL 6 .
} 
Precisamos discutir este resultado.

Vamos começar pelo membro esquerdo da igualdade (34). Sabemos que $F_{\text {crítica }}$ é a força necessária para por a lista da esquerda na iminência de movimento (veja a Fig.4 e considere a lista da direita fixa em sua extremidade a uma parede). Esta é a quantidade de interesse neste problema, pois queremos saber quão difícil é separar as listas. $N$ é o número total de folhas da lista da esquerda 18 e $\mathcal{F}(1)$ é a força total de atrito sobre a folha externa (superior ou inferior) da lista da esquerda (Fig. 4).

A questão é: de que modo podemos atribuir um valor a $\mathcal{F}(1)$ ? Como você verá, esta é, infelizmente, uma limitação do modelo de Alarcón e colaboradores. Não adianta combinarmos, para a folha externa superior da lista da esquerda (Fig. 4), as relações (nesta ordem) (9), (2), (3), (4), (6) e (7), porque obteremos, após simplificações, $\mathcal{F}(1)=3 \mu_{\mathrm{e}} T_{\text {ext }} \operatorname{sen} \theta_{\text {ext }}-$ ou seja, obteremos $\mathcal{F}(1)$ em função de outra quantidade desconhecida: a força $T_{\text {ext }}$ atuando sobre a parte da folha externa situada na zona intermediária (veja a Fig. 6a, considerando que se trata da folha externa superior da lista da esquerda). Então - você pode estar se perguntando - como os autores do PRL [6] resolveram o problema de atribuir um valor a $\mathcal{F}(1)$ ? Afinal, sem um valor para $\mathcal{F}(1)$ não podemos usar a igualdade (34) para prever o valor de $F_{\text {crítica }}$ em uma determinada situação, percebe? Repetimos: esta é realmente uma limitação do modelo de Alarcón e colaboradores. Mas vamos ver como os autores do PRL lidaram com esse problema.

Alarcón e colaboradores afirmaram em seu artigo 6 que, naquele trabalho, buscaram capturar a física essencial necessária à elucidação do enigma da dificuldade de se separar duas listas telefônicas com suas folhas intercaladas. Claro, se tivessem conseguido obter uma expressão para a força $F_{\text {crítica }}$ em função de parâmetros que pudessem ser, todos, previamente medidos, teria sido excelente. Mas o objetivo apresentado ainda pôde ser alcançado. Vamos mostrar de que forma. Como dissemos na primeira seção, em seu trabalho Alarcón e colaboradores não apenas desenvolveram o modelo que estamos descrevendo em detalhes nesta seção, mas também realizaram experimentos, e verificaram que os resultados experimentais obtidos eram bem descritos pela igualdade (34) com $\mathcal{F}(1)=0,01 \mathrm{~N}$, e com o coeficiente de atritd 19 sendo usado como um parâmetro livre para o ajuste da curva $F_{\text {crítica }}=F_{\text {crítica }}(\alpha)$ em cada série de medições (veja a Fig. 4 do PRL 6]). Em cada série, foi mantido fixo o número total de folhas, $N$, e variada a distância de separação, d (veja a Fig. 2 do PRL). Mas por que escolheram esse valor para $\mathcal{F}(1)$ ? Pois é, eles não disseram. Contudo, coincidência ou não, verificamos que o valor $0,01 \mathrm{~N}$ usado para $\mathcal{F}(1)$ é a potência de base 10 mais próxima do peso da folha de papel usada por Alarcón e colaboradores em seu experimento. Acompanhe: Os

\footnotetext{
${ }^{18}$ Lembre-se de que estamos trabalhando, aqui, com $N$ ímpar (veja, novamente, a Fig. 4. Mas, devido às várias aproximações introduzidas, é fácil concluir que o resultado expresso na igualdade 34 também é válido para $N$ par.

${ }^{19}$ Veja, novamente, a nota de rodapé número 8.
}

autores do PRL trabalharam com folhas, da marca Inacopia, com espessura de 0,10 mm. Embora não tenham informado, no artigo, a densidade superficial das folhas usadas, encontramos folhas dessa marca, e com espessura em torno de $0,10 \mathrm{~mm}$, com densidade superficial ("gramatura") de $70,75,80 \mathrm{ou} 90 \mathrm{~g} / \mathrm{m}^{2}$. Como os experimentos foram realizados com folhas com dimensões $12 \mathrm{~cm} \times 25 \mathrm{~cm}$, segue que o peso de cada folha usada é de, no mínimo, $0,070 \mathrm{~kg} / \mathrm{m}^{2} \times 0,12 \mathrm{~m} \times 0,25 \mathrm{~m} \times 9,81 \mathrm{~m} / \mathrm{s}^{2} \approx 0,021 \mathrm{~N}$ e de, no máximo, $0,026 \mathrm{~N}$, que são valores da mesma ordem de grandeza que $0,010 \mathrm{~N}$.

A solução apresentada no PRL para o problema da atribuição de um valor para $\mathcal{F}(1)$ nos ensina um pouco mais sobre como os físicos trabalham. Se você é um estudante que tem a tendência de enxergar a física como se fosse matemática, a solução apresentada pode ter lhe deixado um pouco frustrado, mas, saiba, esse tipo de procedimento é mais comum do que você imagina.

Muito bem, passemos ao membro direito da igualdade (34). De início, vamos examinar para que valor ele tende quando $\alpha$ tende a 0 . Mas, antes, vamos analisar o que significa, fisicamente, fazer $\alpha$ tender a 0 .

Observe a definição em (26). Certamente não faz sentido fazermos $N$ tender a 0 , concorda? Até porque chegamos à igualdade (34) considerando $N \gg 1$ (ou, em termos práticos, $N \gtrsim 55$ ). Por outro lado, embora faça sentido, não é interessante fazermos $\mu_{\mathrm{e}}$ tender a 0 , pois sem atrito temos ${ }^{20} \mathcal{F}(1)=0$ e, de acordo com a igualdade $(33), F_{\text {crítica }}=0$. Então, podemos analisar a razão $\epsilon / d$ : $\alpha$ tende a 0 quando essa razão tende a zero. Podemos imaginar um valor de $d$ fixo, e valores para $\epsilon$ progressivamente menores - ou seja, podemos imaginar folhas cada vez mais finas, sem alteração do valor de $\mu_{\mathrm{e}}$. Trata-se é claro, de uma experiência de pensamento; sua realização experimental pode ser inviável. Mas é uma experiência de pensamento coerente com o modelo de Alarcón e colaboradores. Perceba que quando a razão $\epsilon / d$ tende a 0 (e, portanto $\alpha \rightarrow 0$ ), as partes das folhas nas regiões intermediárias (veja a Fig.4 tendem a ficar paralelas às suas partes nas regiões das braçadeiras e na zona de contato; e isso, é claro, faz com que o efeito de amplificação do atrito tenda a zero.

Pois bem, agora que entendemos o que significa, fisicamente, fazer $\alpha$ tender a 0 , vamos examinar para que valor o membro direito da igualdade (34) tende quando $\alpha \rightarrow 0$. Se o limite superior da integral em 32 é muito próximo de 0 (que é o limite inferior daquela integral), o integrando é aproximadamente igual a 1 no intervalo de integração, e, portanto, temos

$$
\operatorname{erf}(x) \approx \frac{2}{\sqrt{\pi}} x, \text { para } 0<x \ll 1 .
$$

Daí,

$$
\operatorname{erf}(\sqrt{\alpha}) \approx \frac{2}{\sqrt{\pi}} \sqrt{\alpha}=\sqrt{\frac{4 \alpha}{\pi}}, \text { para } 0<\alpha \ll 1 .
$$

\footnotetext{
${ }^{20}$ Lembre-se de que $\mathcal{F}(1)$ é a força total de atrito sobre uma das duas folhas externas da lista da esquerda (veja a Fig. 4 .
} 
Como $\exp (\alpha) \approx 1$ para $0<\alpha \ll 1$, obtemos

$$
\sqrt{\frac{\pi}{4 \alpha}} \exp (\alpha) \operatorname{erf}(\sqrt{\alpha}) \approx 1, \text { para } 0<\alpha \ll 1,
$$

ou, equivalentemente,

$$
\sqrt{\frac{\pi}{4 \alpha}} \exp (\alpha) \operatorname{erf}(\sqrt{\alpha}) \rightarrow 1, \text { quando } \alpha \rightarrow 0
$$

Portanto, quando $\alpha$ tende a 0 , o segundo membro da igualdade (34) tende a 1. E o que isso nos diz? Nos diz que

$$
\frac{F_{\text {crítica }}}{N \mathcal{F}(1)} \rightarrow 1, \text { quando } \alpha \rightarrow 0
$$

Este resultado corresponde ao esperado, pois se o parâmetro de amplificação $\alpha$ tende a zero (tenha em mente a razão $\epsilon / d$ tendendo a 0 ), as forças totais de atrito sobre as folhas da lista da esquerda (na zona de contato) tendem a ser iguais entre si, e, portanto, $F_{\text {crítica }} \rightarrow N \mathcal{F}(1)$.

Na Fig. 7 temos o gráfico de

$$
g(\alpha) \equiv \sqrt{\frac{\pi}{4 \alpha}} \exp (\alpha) \operatorname{erf}(\sqrt{\alpha})
$$

além dos gráficos, separadamente, de $g_{1}(\alpha)=$ $\sqrt{\pi / 4 \alpha} \exp (\alpha)$ e $g_{2}(\alpha)=\operatorname{erf}(\sqrt{\alpha})$. Podemos ver na figura que, de fato, $g(\alpha)$ tende a 1 quando $\alpha$ tende a 0 . Também podemos ver que $g_{2}(\alpha)$ tende rapidamente a 1 quando aumentamos o valor de $\alpha$, e, assim, $g(\alpha)$ se aproxima rapidamente de $g_{1}(\alpha)$.

Nos experimentos realizados por Alarcón e colaboradores, os menores valores obtidos para $\alpha$ ficaram em torno de 0,5 , enquanto os maiores, em torno 8,5 (veja a Fig. 4 do PRL [6]). Para $\alpha=8,5$, temos $g(\alpha) \approx 1490$, que é um valor muito acima daqueles apresentados na Fig. 7. e mostra como $g(\alpha)$ cresce de forma extremamente

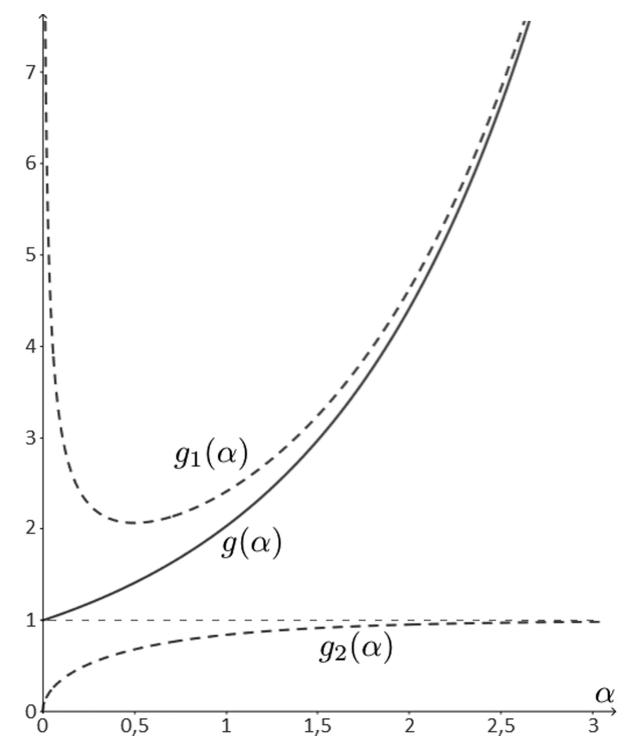

Figura 7: Gráficos de $g(\alpha)=\sqrt{\pi / 4 \alpha} \exp (\alpha) \operatorname{erf}(\sqrt{\alpha}), g_{1}(\alpha)=$ $\sqrt{\pi / 4 \alpha} \exp (\alpha)$ e $g_{2}(\alpha)=\operatorname{erf}(\sqrt{\alpha})$. rápida com $\alpha$. Contudo, mesmo quando temos $\operatorname{erf}(\sqrt{\alpha})$ praticamente igual a 1 , não se trata de um crescimento exponencial, devido ao fator $\sqrt{\pi / 4 \alpha}$. Para $\alpha=8,5$ te$\operatorname{mos} \exp (\alpha) \approx 4910$, que é mais que o triplo de 1490 , e a diferença (relativa ou absoluta) entre $\exp (\alpha)$ e $g(\alpha)$ só aumenta, à medida que o valor de $\alpha$ aumenta.

Concluímos aqui nossa descrição detalhada do modelo de Alarcón e colaboradores. Na próxima seção, apresentaremos o cálculo da força $F_{\text {crítica }}^{\star}$ que põe na iminência de movimento dois grupos de folhas na configuração apresentada na Fig. 3a, e compararemos a expressão obtida com aquela para $F_{\text {crítica }}$ na igualdade (34).

\section{Cálculos para listas sem as lombadas, mas sob ação da gravidade}

A Fig. 87 exibe a numeração que escolhemos para as folhas dos grupos da esquerda e da direita apresentados na Fig. 3a. Observe que acima da enésima folha do grupo da esquerda repousam $n-1$ folhas do mesmo grupo e $n$ folhas do grupo da direita, totalizando $2 n-1$ folhas. Sendo $m$ a massa de cada folha e $g$ o módulo da aceleração da gravidade, podemos imediatamente concluir que o bloco formado por essas $2 n-1$ folhas, que tem massa $(2 n-1) m$, empurra para baixo a folha $n$ do grupo da esquerda com força de móduld 21

$$
f_{\mathrm{n}_{n, \text { sup }}}=(2 n-1) m g,
$$

e se o sistema está na iminência de movimento, a força de atrito estático exercida sobre a folha $n$ do grupo da

(a)

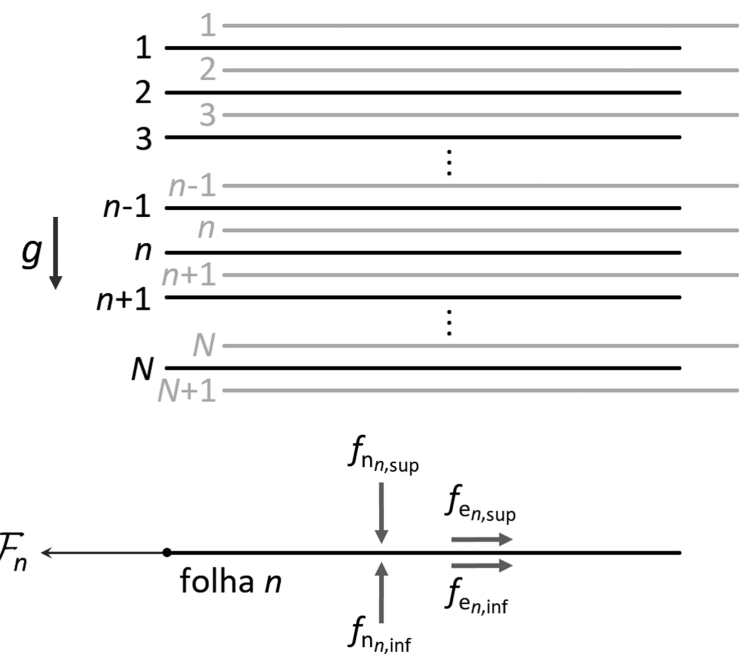

Figura 8: (a) Numeração das folhas intercaladas na configuração apresentada na Fig. 3á. Há $N$ folhas no grupo da esquerda e $N+1$ folhas no grupo da direita. O espaçamento entre as folhas foi introduzido apenas para facilitar a visualização, e a direção do vetor aceleração da gravidade está indicada na figura. (b) Forças (além do peso) atuando sobre a folha $n$ do grupo da esquerda.

${ }^{21}$ Estamos supondo desprezíveis, ou mesmo nulas, as componentes verticais das forças exercidas pelos pinos (veja a Fig. 3a) sobre as folhas do grupo da esquerda. 
esquerda pela folha $n$ do grupo da direita tem móduld 22

$$
f_{\mathrm{e}_{n, \text { sup }}}=\mu_{\mathrm{e}} f_{\mathrm{n}_{n, \text { sup }}}=(2 n-1) \mu_{\mathrm{e}} m g
$$

(veja a Fig. 8b).

A força vertical que sustenta o bloco formado pelas $n$ primeiras folhas do grupo da esquerda e pelas $n$ primeiras folhas do grupo da direita tem módulo (veja a Fig. 8p)

$$
f_{\mathrm{n}_{n, \text { inf }}}=(2 n) m g,
$$

e, na iminência de movimento, a força de atrito estático exercida sobre a folha $n$ do grupo da esquerda pela folha $n+1$ do grupo da direita tem módulo

$$
f_{\mathrm{e}_{n}, \mathrm{inf}}=\mu_{\mathrm{e}} f_{\mathrm{n}_{n, \mathrm{inf}}}=(2 n) \mu_{\mathrm{e}} m g .
$$

O equilíbrio da folha $n$ do grupo da esquerda (considerando-se a iminência de movimento) nos leva à igualdade (veja a Fig.8p)

$$
\mathcal{F}_{n}=f_{\mathrm{e}_{n, \text { sup }}}+f_{\mathrm{e}_{n, \text { inf }}},
$$

sendo $\mathcal{F}_{n}$ a força exercida pelos pinos (veja a Fig. 3 a) sobre aquela folha. Substituindo 41) e 42 em (43), obtemos

$$
\mathcal{F}_{n}=(4 n-1) \mu_{\mathrm{e}} m g \text {. }
$$

A força $F_{\text {crítica }}^{\star}$ que põe na iminência de movimento o grupo de folhas da esquerda na configuração apresentada na Fig. 3 a (considere fixo o grupo de folhas da direita) é então, simplesmente,

$$
F_{\text {crítica }}^{\star}=\sum_{n=1}^{N} \mathcal{F}_{n}=\sum_{n=1}^{N}(4 n-1) \mu_{\mathrm{e}} m g .
$$

Segue que 23

$$
F_{\text {crítica }}^{\star}=\mu_{\mathrm{e}} m g[4 \underbrace{\left(\sum_{n=1}^{N} n\right)}_{\frac{(1+N) N}{2}}-\underbrace{\left(\sum_{n=1}^{N} 1\right)}_{N}],
$$

e, portanto,

$$
F_{\text {crítica }}^{\star}=\left(2 N^{2}+N\right) \mu_{\mathrm{e}} m g .
$$

O cálculo está feito. Mas é interessante enxergarmos esta dependência quadrática de $F_{\text {crítica }}^{\star}$ em relação a $N$ a partir da igualdade

$$
F_{\text {crítica }}^{\star}=N \overline{\mathcal{F}}
$$

em que

$$
\overline{\mathcal{F}} \equiv \frac{1}{N} \sum_{n=1}^{N} \mathcal{F}_{n}
$$

\footnotetext{
$2 \overline{\text { Estamos considerando } \mu_{\mathrm{e}}}$ constante, representando uma espécie de valor médio, já que, no caso de atrito de papel sobre papel, o valor do coeficiente de atrito estático diminui quando aumentamos o valor da força normal (ou seja, $\mu_{\mathrm{e}}$ é uma função decrescente de $n$ ). Trata-se, portanto, do mesmo tipo de simplificação introduzido por Alarcón e colaboradores em seu modelo 6] (veja a nota de rodapé número 8 ).

${ }^{23}$ Observe que usamos, para o primeiro somatório, a fórmula da soma dos termos de uma progressão aritmética.
}

é a força média com que as folhas do grupo da esquerda são puxadas (na iminência de movimento). Como $\mathcal{F}_{n}$ é uma função afim de $n$ (veja a igualdade 44 ) ${ }^{24}$ segue que

$$
\begin{aligned}
\overline{\mathcal{F}} & =\frac{\mathcal{F}_{1}+\mathcal{F}_{N}}{2}=\frac{3 \mu_{\mathrm{e}} m g+(4 N-1) \mu_{\mathrm{e}} m g}{2} \\
& =(2 N+1) \mu_{\mathrm{e}} m g
\end{aligned}
$$

Portanto, essa relação afim entre $\overline{\mathcal{F}}$ e $N$ leva, através da igualdade (46), à relação quadrática entre $F_{\text {crítica }}^{\star}$ e $N$ na igualdade 45). Em outras palavras: a relação quadrática entre $F_{\text {crítica }}^{\star}$ e $N$, em 45 , resulta da existência de $N$ folhas no grupo da esquerda (que está sendo puxado) $e$ da relação afim entre a força média $\overline{\mathcal{F}}$ com que as folhas são puxadas e $N$.

Você pode facilmente verificar que para $N \geq 10$ temos $2 N^{2}+N \approx 2 N^{2}$ com um erro relativo percentual $\lesssim 5 \%$ (e para $N=50$ o erro relativo percentual é de aproximadamente 1\%). Assim, considerando que não trabalharemos com $N<10$, podemos reescrever a igualdade (45) como

$$
F_{\text {crítica }}^{\star} \approx 2 N^{2} \mu_{\mathrm{e}} m g \quad(N \geq 10) \text {. }
$$

Agora, vamos comparar as igualdades (34) e (47).

O que queremos, na verdade, é comparar as dificuldades de se separar duas listas telefônicas com e sem as lombadas (veja as Figs.1] e 3a). Mas esta comparação não é imediata. Veremos por quê.

Em primeiro lugar, lembre-se de que no modelo de Alarcón e colaboradores não é considerado o efeito da gravidade (por ser supostamente desprezível - o que analisaremos ainda nesta seção). Assim, ao compararmos as igualdades (34) e 47) estamos buscando comparar as dificuldades de se separar as listas com as lombadas, mas com a gravidade "desligada", e sem as lombadas, mas com a gravidade "ligada".

Lembre-se também de que o modelo de Alarcón e colaboradores não nos fornece uma expressão para a força total de atrito $\mathcal{F}(1)$ sobre a folha externa (superior ou inferior) da lista da esquerda, sendo então $\mathcal{F}(1)$ (como dizem os autores do PRL [6]) uma condição de contorno crucial do problema. Como comentamos na seção anterior, em seu trabalho Alarcón e colaboradores verificaram que os resultados experimentais obtidos eram bem descritos pela igualdade 34 com $\mathcal{F}(1)=0,01 \mathrm{~N}$, e com o coeficiente de atrito sendo usado como um parâmetro livre para o ajuste da curva $F_{\text {crítica }}=F_{\text {crítica }}(\alpha)$ em cada série de medições, sendo que em cada série foi mantido fixo o número total $N$ de folhas e variada a distância de separação $d$ (veja a Fig. (4). Trabalharemos então com uma daquelas séries: a série $N=100$ - única para a qual os autores do PRL informaram, no artigo, o valor do coeficiente de atrito obtido por ajuste: $0,73 \pm 0,02$.

Mas, infelizmente, temos ainda uma dificuldade: em princípio não estamos autorizados a usar este valor para $\mu_{\mathrm{e}}$ na igualdade (47). A afirmativa de que o valor 0,73 obtido por ajuste para o coeficiente de atrito, para a série

\footnotetext{
24 Dizemos que $y$ é uma função afim de $x$ se $y=a x+b$, com $a \neq 0$. No caso particular em que $b=0$, temos a chamada função linear.
} 
$N=100$, representa um valor médio é mais complexa do que pode parecer à primeira vista. Mesmo para um determinado valor da distância de separação $d$, o módulo da força normal sobre uma das faces de uma folha aumenta no sentido das folhas externas para as folhas mais centrais de cada lista, e, com isso, diminui o valor do coeficiente de atrito. Ou seja, mesmo para um $d$ fixo, não há um valor único para o coeficiente de atrito quando passamos de uma folha para outra. E quando o valor de $d$ é modificado, a força normal sobre uma das faces de uma determinada folha também muda, e isso produz uma mudança no valor do coeficiente de atrito para aquelas superfícies em contato. Assim, o valor 0,73 obtido por ajuste representa uma média não para um determinado valor de $d$, mas para uma faixa de valores desta variável. Usarmos este mesmo valor para $\mu_{\mathrm{e}}$ na igualdade (47) em princípio não se justifica. Contudo, podemos trabalhar inicialmente com tal valor para $\mu_{\mathrm{e}}$ em (47) (e lá $\mu_{\mathrm{e}}$ também representa uma espécie de valor médio, já que a força normal aumenta no sentido das folhas superiores para as inferiores na Fig. 3a, e, portanto, o valor do coeficiente de atrito estático entre folhas adjacente diminui nesse mesmo sentido) e em seguida considerar variações de $\mu_{\mathrm{e}}$, para mais e para menos, e observar seu efeito sobre o valor de $F_{\text {crítica }}^{\star}$ (que tem com $\mu_{\mathrm{e}}$ uma relação linear).

Considerando a densidade padrão $\left(80 \mathrm{~g} / \mathrm{m}^{2}\right)$ para folhas de tamanho A4 da marca Inacopia 21 25 as dimensões $12 \mathrm{~cm} \times 25 \mathrm{~cm}$ com que trabalharam Alarcón e colaboradores, a massa de cada folha usada em seu experimento é de 2,4 g. Assim, fazendo $N=100, \mu_{\mathrm{e}}=0,73$, $m=2,4 \mathrm{~g}$ e $g=9,81 \mathrm{~m} / \mathrm{s}^{2}$ em 47 , obtemos

$$
F_{\text {crítica }}^{\star} \approx 344 \mathrm{~N}
$$

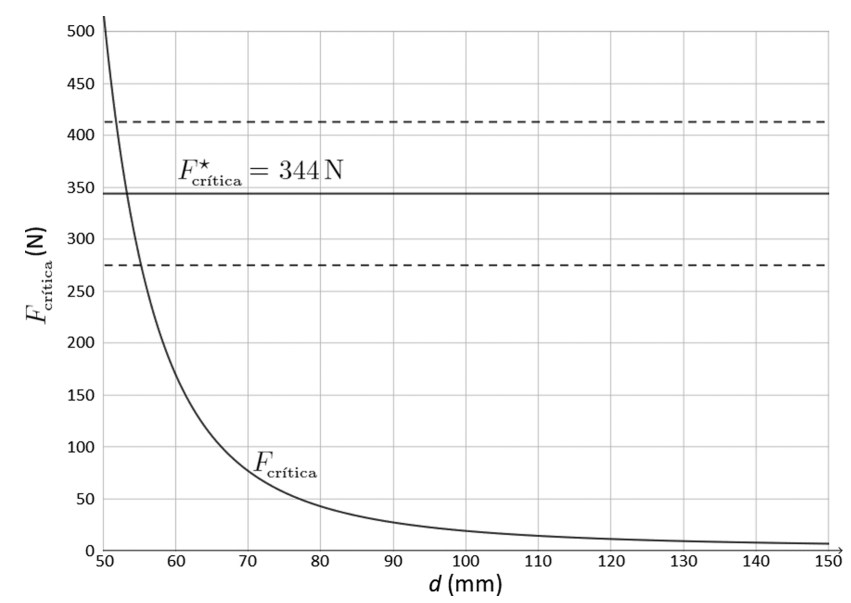

Figura 9: Gráfico de $F_{\text {critica }}$ em função de $d$, a partir da igualdade (34), com $\mu_{\mathrm{e}}=0,73, \epsilon=0,1 \mathrm{~mm}, N=100$ e $\mathcal{F}(1)=0,01 \mathrm{~N}$. E apresentado, para comparação, o valor de $F_{\text {critica }}^{\star}$ a partir da igualdade (47), com $N=100, \mu_{\mathrm{e}}=0,73, m=2,4 \mathrm{~g}$ e $g=$ $9,81 \mathrm{~m} / \mathrm{s}^{2}$. As linhas tracejadas indicam variações de $20 \%$ sobre este valor, para mais e para menos, correspondendo a essas mesmas variações percentuais sobre $\mu_{\mathrm{e}}$.

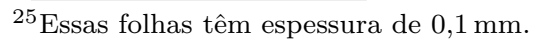

que é uma força consideravelmente alta, concorda? Este valor aparece na Fig.9, que apresenta o gráfico de $F_{\text {crítica }}$, obtido a partir de (34), para a faixa $50 \mathrm{~mm} \leq d \leq$ $150 \mathrm{~mm}$, com $\mu_{\mathrm{e}}=0,73, \epsilon=0,1 \mathrm{~mm}, N=100$ e $\overline{\mathcal{F}}(1)=$ $0,01 \mathrm{~N}$.

Escolhemos o intervalo [50 mm, $150 \mathrm{~mm}$ ] para a distância de separação $d$ porque para a série $N=100$ os resultados experimentais no trabalho de Alarcón e colaboradores [6] são apresentados com $d$ variando de $50 \mathrm{~mm}$ a aproximadamente $225 \mathrm{~mm}$ (veja a figura 2 do PRL), e para $d \gtrsim 150 \mathrm{~mm}$ temos valores para $F_{\text {crítica }}$ muito próximos de zero. Perceba que $F_{\text {crítica }}^{\star}=344 \mathrm{~N}$ só é superada por $F_{\text {crítica }}$ para $d$ próximo de $50 \mathrm{~mm}$, mesmo considerando-se um valor $20 \%$ menor para $\mu_{\mathrm{e}}$ no cálculo de $F_{\text {crítica }}^{\star}$.

Estamos querendo dizer com isso que o efeito da gravidade, no problema da separação de duas listas telefônicas com suas folhas intercaladas, não é desprezível? Não. O que estamos dizendo, por enquanto, é que separar dois grupos de folhas na configuração apresentada na Fig. 3 a não é uma tarefa trivial. Vimos que havendo apenas 100 folhas (do tipo usado por Alarcón e colaboradores) em cada grupo, e considerando $\mu_{\mathrm{e}}=0,73$, são necessários $344 \mathrm{~N}$ de força, e com 400 folhas em cada grupo obtemos (mantendo o mesmo valor para o coeficiente de atrito estático)

$$
F_{\text {crítica }}^{\star} \approx 5500 \mathrm{~N} \text {, }
$$

que é o peso de um objeto de aproximadamente 560 quilogramas! Mesmo reduzindo o valor de $\mu_{\mathrm{e}}$ à metade (ou seja, fazendo $\mu_{\mathrm{e}}=0,73 / 2=0,365$ ), ainda temos que $F_{\text {crítica }}^{\star}$ corresponde ao peso de um objeto de 280 quilogramas. E lembre-se de que estamos considerando folhas com dimensões $12 \mathrm{~cm} \times 25 \mathrm{~cm}$, que são valores menores que aqueles para folhas de papel tamanho A4.

Mas não dá pra comparar o valor para $F_{\text {crítica }}^{\star}$ acima com o que prevê a igualdade (34) para apenas 200 folhas, com $\mu_{\mathrm{e}}=0,73, \epsilon=0,1 \mathrm{~mm}, d=50 \mathrm{~mm}$, e $\mathcal{F}(1)=0,01 \mathrm{~N}$ :

$$
F_{\text {crítica }} \approx 1,6 \times 10^{12} \mathrm{~N}
$$

que é um valor impensável; corresponde ao peso de aproximadamente 30 milhões de elefantes adultos 26 Contudo, reduzindo o coeficiente de atrito estático para $\mu_{\mathrm{e}}=0,73 / 4$, e mantendo os valores dos demais parâmetros, obtemos, a partir de (34),

$$
F_{\text {crítica }} \approx 970 \mathrm{~N}
$$

que é um valor não muito maior que $344 \mathrm{~N}$, obtido a partir de (47) também com $N=200, \mu_{\mathrm{e}}=0,73 / 4, m=2,4 \mathrm{~g}$ e $g=9,81 \mathrm{~m} / \mathrm{s}^{2}$.

Percebe como a comparação entre o que preveem as igualdades (34) e 47) não é algo trivial? Além do mais, a igualdade (34) não foi testada experimentalmente para valores de $F_{\text {crítica }}$ superiores a $1000 \mathrm{~N}$, no trabalho de Alarcón e colaboradores [6]. Então, deve-se ter cautela nessas comparações.

${ }^{26}$ Obviamente, as folhas de papel rasgariam muitíssimo antes desse valor ser alcançado (se ele pudesse ser alcançado). 
O que mais nos interessa, aqui, é mostrar que não é correto afirmar, de maneira absoluta, que a gravidade, pressionando as folhas umas contra as outras, tem efeito desprezível no problema da separação de duas listas telefônicas. Ou seja, mesmo na ausência do efeito de amplificação do atrito descrito no artigo de Alarcón e colaboradores, uma força elevada pode ser necessária para se separar dois grupos de folhas na configuração apresentada na Fig. 3a. Verificamos isso experimentalmente, e os resultados estão apresentados e discutidos na seção seguinte.

\section{Experimento para listas sem as lombadas, mas sob ação da gravidade}

As Figs. 10 a 12 apresentam a montagem experimental realizada para a medição da força $F_{\text {crítica }}^{\star}$ que põe na iminência de movimento dois grupos de folhas na configuração ilustrada na Fig. 3 p.

Trabalhamos com folhas de papel do tipo vergê, da marca Infopel, tamanho A4 $(21,0 \mathrm{~cm} \times 29,7 \mathrm{~cm})$ e densidade de $180 \mathrm{~g} / \mathrm{m}^{2}$, que resultaria em uma massa de $11,2 \mathrm{~g}$ por folha. Com o uso de uma balança digital, medimos as massas de várias folhas, e obtivemos o valor médio de $11,3 \mathrm{~g}$ por folha, com um desvio padrão de $0,2 \mathrm{~g}$. Também medimos as espessuras de várias folhas, com o uso de um micrômetro de $0,01 \mathrm{~mm}$ de precisão, e o resultado

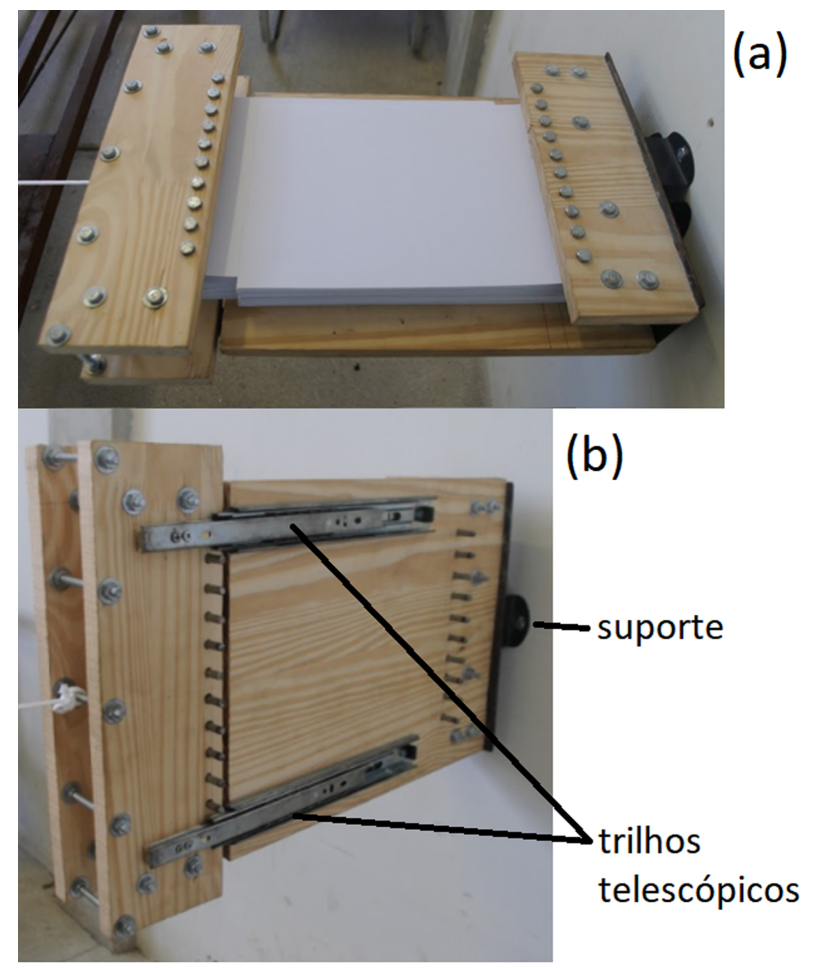

Figura 10: (a) Montagem experimental relativa à ilustração apresentada na Fig. 3a. (b) Estrutura girada de $90^{\circ}$. Nesta foto aparecem os trilhos telescópicos que conectam as duas partes da montagem, e o suporte que fixa uma dessas partes à parede. Um parafuso central (que não aparece na foto) no suporte permite o giro.

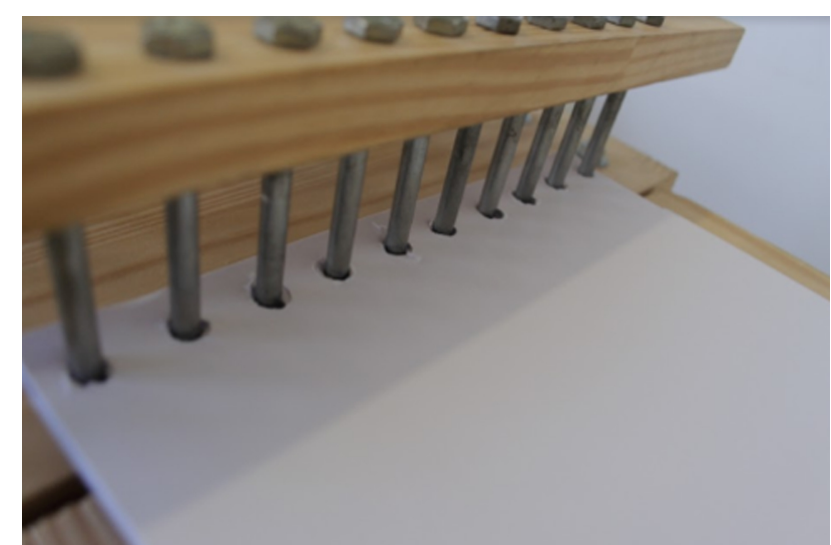

Figura 11: Pinos atravessando algumas folhas de papel, previamente perfuradas.

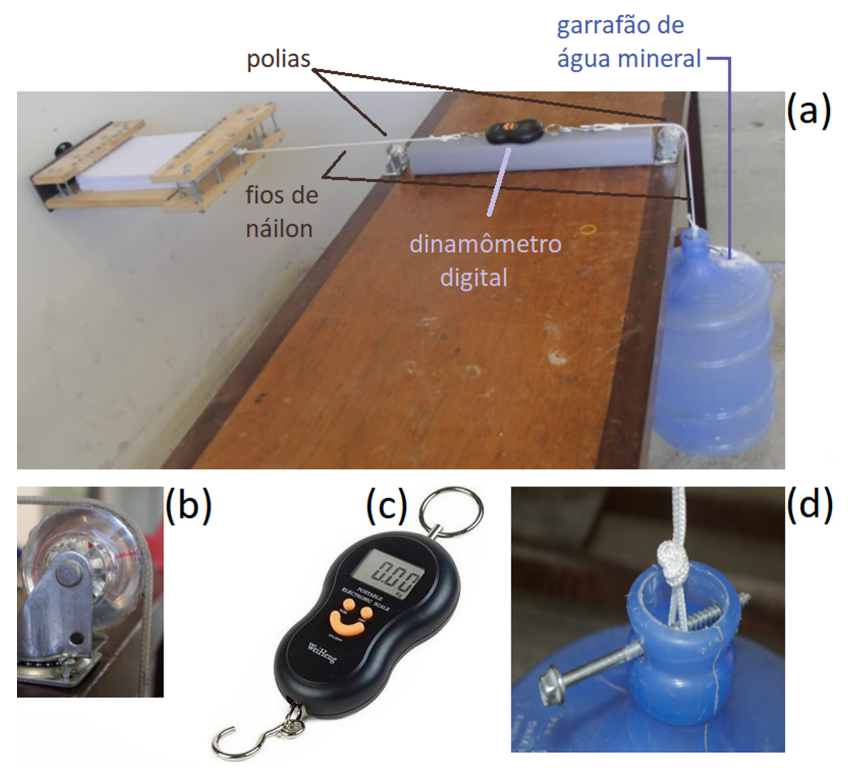

Figura 12: (a) Montagem experimental (fotografada pelo lado oposto ao apresentado nas fotos da Fig. 10). Detalhes: (b) polia da direita, (c) dinamômetro digital utilizado e (d) parafuso atravessando a boca do garrafão, ao qual está amarrado um dos fios de náilon trançado.

obtido na maioria das medições foi $0,29 \mathrm{~mm}$. A diferença de rugosidade entre os dois lados de uma mesma folha de papel vergê foi observada, e as medições foram realizadas com as folhas dispostas, umas sobre as outras, de modo que a face mais lisa de uma folha estava sempre em contato com a face mais rugosa de uma folha adjacente (do outro grupo).

O dinamômetro digital utilizado (veja a Fig. 12. mite leituras, em uma escala de massa, de até $50 \mathrm{~kg}$, com precisão de $5 \mathrm{~g}$ na faixa de 0 a $10 \mathrm{~kg}$ e de $10 \mathrm{~g}$ na faixa de $10 \mathrm{~kg}$ a $50 \mathrm{~kg}$. Ele foi previamente testado, com massas conhecidas, e em todas as medições apresentou resultados de acordo com o esperado.

A força aplicada sobre a parte da montagem que contém as folhas foi inicialmente variada mudando-se lentamente a quantidade de água no garrafão mostrado 
na Fig. 12 a. Enquanto um operador adicionava água ao garrafão (sempre a uma taxa pequena), um segundo operador observava as leituras no dinamômetro, ao final anotando o último valor exibido antes que o sistema entrasse em movimento (algumas vezes um pequeno movimento, seguido de um novo estado de repouso, devido ao fenômeno de "stick-slip", ou "gruda-escorrega", citado na primeira seção deste artigo). Quando forças mais altas foram necessárias, foi posto no garrafão um pouco de areia e brita (pedra britada), e então água foi lentamente adicionada até o sistema entrar em movimento.

A Fig.13 apresenta as medidas da força $F_{\text {crítica }}^{\star}$ em função do número $N$ de folhas em cada um dos grupos ilustrados na Fig. 3a (veja também a fotografia na Fig. 10a). Através de um ajuste da curva $F_{\text {crítica }}^{\star}=c N^{2}$ aos dados experimentais, obtivemos $c=0,01538 \mathrm{kgf}$, o que nos leva, através da igualdade (47), com $m=11,3 \mathrm{~g}$, a $\mu_{\mathrm{e}}=0,6 8 \longdiv { { } ^ { 2 7 } 2 8 }$ Perceba que esse valor corresponde a uma espécie de média do coeficiente de atrito estático entre folhas adjacentes, mas não para cada valor de $N$, e sim para a série $N=15,20,25,30,35,40,45$. Você deve lembrar, trata-se de uma simplificação semelhante à realizada por Alarcón e colaboradores em seu trabalho [6].

O que nos interessa, aqui, é mostrar que a igualdade (47) se aplica razoavelmente bem aos dados experimentais obtidos e apresentados na Fig.13 Observe que foram necessários mais de $30 \mathrm{kgf}$ para separar dois grupos com apenas 45 folhas, cada. Trata-se de uma força considerá-

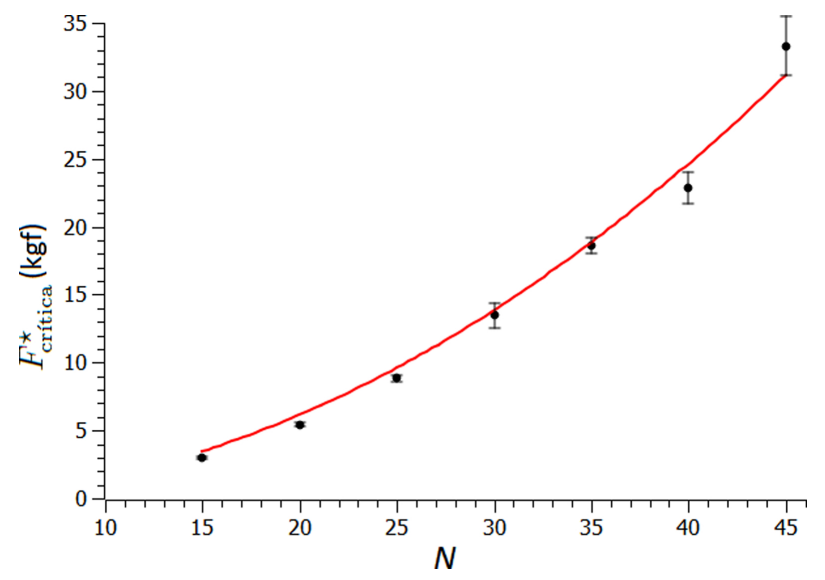

Figura 13: Medidas de $F_{\text {critica }}^{\star}$, em função do número $N$ de folhas em cada grupo. As barras verticais correspondem aos desvios padrões (foram realizadas 5 medições para cada valor de $N$ ), e a linha contínua resultou do ajuste da curva $F_{\text {critica }}^{\star}=c N^{2}$ aos dados experimentais. $\mathrm{O}$ valor obtido para a constante $c$, através do ajuste, foi $c=0,01538 \mathrm{kgf}$.

27 Consideramos mais conveniente o uso, nesta seção, da unidade quilograma-força (kgf), em vez de Newton (N). Mas a conversão de kgf para $\mathrm{N}$ é trivial. Por exemplo: 0,01538 $\mathrm{kgf}=0,01538 \times 9,81$ $\mathrm{N}=0,151 \mathrm{~N}$.

28 A título de comparação, um ajuste da curva $F_{\text {crítica }}^{\star}=c N^{2}+$ $\frac{c}{2} N$ (observe a igualdade 45) aos dados experimentais forneceu $c=0,01518 \mathrm{kgf}$, o que nos leva, através da igualdade 45, com $m=11,3 \mathrm{~g}$, a $\mu_{\mathrm{e}}=0,67$, que é um valor muito próximo de 0,68 (as duas curvas ficam praticamente sobrepostas, na Fig.13. Nenhuma surpresa, já que para $N>10$ temos em 47 uma boa aproximação para a expressão em 45 . vel. Mantendo-se o mesmo valor para $\mu_{\mathrm{e}}$ e aumentando-se o número de folhas em cada grupo para 200, seria necessária mais de meia tonelada-força para separar os dois grupos de folhas. Ou seja (e mais uma vez), mesmo na ausência do efeito de amplificação do atrito descrito no artigo de Alarcón e colaboradores, uma força muito elevada pode ser necessária para se separar dois grupos de folhas na configuração apresentada na Fig. 3a.

Verificamos que girando de $90^{\circ}$ a estrutura apresentada na Fig. 10a, pondo-a na orientação apresentada na Fig. 10p, os dois grupos de folhas eram facilmente separados. A força necessária à separação variou de aproximadamente $0,5 \mathrm{kgf}$, para $N=15$, a aproximadamente $2,3 \mathrm{kgf}$, para $N=45$. Essa resistência não-nula à separação é efeito de forças de adesão entre folhas adjacentes. Mas não havendo a força da gravidade pressionando as folhas umas contra as outras, a força necessária à separação dos dois grupos de folhas caiu consideravelmente.

A montagem experimental apresentada nesta seção demandou um esforço considerável para sua conclusão. Não se trata, portanto, de uma atividade que possa ser rapidamente preparada por um(a) docente para realização com seus alunos em uma escola ou em uma instituição de nível superior. Contudo, uma montagem bem mais simples (embora bem menos robusta) foi apresentada em um artigo publicado em 2017 na revista Physics Education 22]. Sugerimos aos professores interessados na realização de uma atividade experimental semelhante à que apresentamos nesta seção que consultem aquele artigo. Contudo, deve-se estar atento à análise simplista que os autores fizeram dos resultados experimentais obtidos. O maior problema é que para cada série de medições, os autores tentaram ajustar uma linha reta às medidas da força necessária à separação dos dois grupos de folhas, em função do número total de folhas. Ou seja, não consideraram nem a expressão (34) obtida por Alarcón e colaboradores no PRL [6] - artigo que eles citam -, nem fizeram uso de uma expressão que desenvolveram, equivalente à que temos na igualdade 47).

\section{Conclusão}

Neste trabalho, analisamos em detalhes o problema da separação de duas listas telefônicas com folhas intercaladas, dando especial atenção a um modelo teórico desenvolvido por uma equipe de físicos e publicado, juntamente com resultados experimentais, em uma conceituada revista científica 6]. Acreditamos ter contribuído para tornar aquele modelo compreensível a um universo maior de estudantes, exigindo dos mesmos apenas uma formação básica em mecânica newtoniana e cálculo diferencial e integral, típica do primeiro ano de um curso de graduação em física ou engenharia.

Também propusemos uma modificação naquele problema, dispondo os dois grupos de folhas perpendicularmente ao vetor aceleração da gravidade e em uma configuração (veja a Fig. 3 a) que equivale à retirada das lombadas das listas. Mostramos - teórica e experimentalmente - que, ao contrário do que o artigo supracitado 6] parece sugerir, mesmo sem o efeito de amplificação do 
atrito (que não existe na configuração apresentada na Fig. 3a) a separação dos dois grupos de folhas pode exigir forças de intensidades elevadas.

\section{Agradecimento}

Agradecemos aos professores Ernesto Arcenio Valdés Rodriguez, do NFD-UFPE, e Pedro Hugo de Figueirêdo, do DF-UFRPE, por suas contribuições para este trabalho. Agradecemos também ao revisor, por suas importantes sugestões.

\section{Material suplementar}

O seguinte material suplementar está disponível online:

Material Suplementar - Obtenção da igualdade (12) do artigo principal.

\section{Referências}

[1] https://youtu.be/bCTLOPQP0j0, acessado em jun. 2019.

[2] https://youtu.be/oMUDUmJ-d5s acessado em jun. 2019.

[3] https://www.imdb.com/title/tt1266951 acessado em jun. 2019.

[4] https://youtu.be/AX_1COjLCTo, acessado em jun. 2019.

[5] https://youtu.be/qjKpQxlIlUw acessado em jun. 2019.

[6] H. Alarcón, T. Salez, C. Poulard, J.F. Bloch, E. Raphaël, K. Dalnoki-Veress e F. Restagno, Physical Review Letters 116, 015502 (2016).

[7] H.P. Jost, Tribology and Lubrication Technology 62, 24 (2006).

[8] https://www.publico.pt/2016/01/20/ciencia/ noticia/como-e-que-se-sustem-um-carro-no-arpreso-a-duas-listas-telefonicas-1720782, acessado em jun. 2019.

[9] https://www.improbable.com/about/, acessado em jun. 2019.

[10] https://www.improbable.com/ig/ acessado em jun. 2019.

[11] https://www.improbable.com/2016/01/09/newmathematical-model-helps-explain-the-strengthof-interleaved-phonebooks/, acessado em jun. 2019.

[12] https://physicstoday.scitation.org/pto/info/ submit, acessado em jun. 2019.

[13] K. Dalnoki-Veress, T. Salez e F. Restagno, Physics Today 69, $74(2016)$.

[14] https://www.improbable.com/2016/06/14/thehercules-number-how-a-dimensionless-physicalparameter-got-its-name/, acessado em jun. 2019.

[15] R. Leine, D. van Campen, A. de Kraker e L. van den Steen, Nonlinear Dynamics 16, 41 (1998).

[16] T. Baumberger e C. Caroli, Advances in Physics 55, 279 (2006).

[17] F. Heslot, T. Baumberger, B. Perrin, B. Caroli e C. Caroli, Physical Review E 49, 4973 (1994).
[18] J. Crassous, L. Bocquet, S. Ciliberto e C. Laroche, Europhysics Letters 47, 562 (1999).

[19] D. Halliday, R. Resnick e J. Walker, Fundamentos de Física (LTC, Rio de Janeiro, 2012).

[20] http://www.romanfrigg.org/writings/Models_in _ Physics_REP.pdf acessado em jun. 2019.

[21] http://inacopia-paper.com/category/elite/, acessado em maio 2019.

[22] N. Balta e A. Çetin, Physics Education 52, 035006 (2017). 